\title{
The Influence of Force Application to the Teeth upon Tension Development of the Masseter and Digastric Muscles of the Cat
}

Frederick R. Merg

Loyola University Chicago

Follow this and additional works at: https://ecommons.luc.edu/luc_theses

Part of the Medicine and Health Sciences Commons

\section{Recommended Citation}

Merg, Frederick R., "The Influence of Force Application to the Teeth upon Tension Development of the Masseter and Digastric Muscles of the Cat" (1967). Master's Theses. 2096.

https://ecommons.luc.edu/luc_theses/2096

This Thesis is brought to you for free and open access by the Theses and Dissertations at Loyola eCommons. It has been accepted for inclusion in Master's Theses by an authorized administrator of Loyola eCommons. For more information, please contact ecommons@luc.edu. (c) (i) $(9)$

This work is licensed under a Creative Commons Attribution-Noncommercial-No Derivative Works 3.0 License. Copyright ( 1967 Frederick R. Merg 
THE INFLUENCE OF FORCE APPLICATION TO THE TEETH UPON TENSION DEVELOPMENT OF THE MASSETER AND DIGASTRIC MUSCLES OF THE CAT

BY

FREDERICK R. MERG

A THESIS SUBMITTED TO THE FACULTY OF THE GRADUATE SCHOOL OF LOYOLA UNIVERSITY IN PARTIAL FULFILLMENT OF THE REQUIREMENTS FOR THE DEGREE OF MASTER OF SCIENCE

JUNE 


\section{ACKNOWLEDGEMENTS}

My gratitude and appreciation is given to the following persons for their significant contributions to this investigation.

To Douglas C. Bowman, M.S., Ph.D., Professor of Physiology, Loyola University for creating an academic climate calculated to provide a challenging problem, encouragement of individual thought, and supplying generous quantities of knowledge and advice.

To Joseph R. Jarabak, D.D.S., Ph.D., Professor of Orthodontics, Loyola University, whose acceptance of this student in the graduate orthodontic program made this study possible.

To Wesley H. Ardoin, D.D.S., my co-worker, whose determination and clear thinking tempered with tact and humor served as a source of inspiration throughout the experiment.

To Dona, my wife, who editted and typed this manuscript. Her unwavering support and encouragement have made the last two years the best of my life. 
TABLE OF CONTENTS

CHAPTER

PAGE

I. INTRODUCTION AND STATEMENT OF THE PROBLEM . . . . . . . . . . . . . . 1

II. REVIEW OF THE LITERATURE . . . . . . . . . 2

III. METHODS AND MATERIALS:

A. Anesthetic Administration . . . . . . . 14

B. Surgical Exposure of the Masseter and Digastric Muscles... . . . . . 18

C. Force Application . . . . . . . . . 23

D. Transducers and Physiograph . . . . . 33

IV. FINDINGS . . . . . . . . . . . . . 40

V. DISCUSSION . . . . . . . . . . . . 68

VI. SUMMARY AND CONCLUSIONS . . . . . . . . . 81

BIBLIOGRAPHY . . . . . . . . . . . 84 
LIST OF FIGURES

FIGURE

PAGE

1. Anesthesia System . . . . . . . . . . . 15

2. Stereotaxic Device . . . . . . . . . . . 21

3. Torque Instrument . . . . . . . . . . . 25

4. Torque Wrench (Side View) . . . . . . . . 26

5. Torque Wrench (Top View) - . • . . . . . . . 27

6. Hyaraulic Instrument . . . . . . . . . . . . 30

7. Combined Utilization of Torque and Hydraulic Systems . . . . . . . . . . . 32

8. Myographs . . . . . . . . . . . . . . . 34

9. Pen Recorder Section of Physiograph . • • . . 36

10. Tension of the Masseter and Digastric Muscles Plotted Against Low Force Application to the Ipsilateral Canine Tooth. Illustrates Reciprocal Innervation. Cat 09306 . • . • •

11. Tension of the Masseter and Digastric Plotted Against Low Force Application to the Ipsilateral Canine Tooth. Illustrates Reciprocal Action. Cat 11116 . . . . . . . . .

12. Tension of the Masseter and Digastric Muscles Plotted Against Low Force Application to the Ipsilateral Canine Tooth. Illustrates Reciprocal Action. Cat 11146 . . . . . . . .

13. Tension of the Masseter Muscle Plotted Against Low Force Application to the Ipsilateral Canine Tooth. Cats 12026, 01137 . . . . . 
14. Digastric Tension Plotted Against Low Force Application to the Ipsilateral Canine Tooth Cats 11286, 12026 . . . . . . . . . . .

15. Digastric Tension Plotted Against Low Force Application to the Ipsilateral Canine Tooth Cat 12156 . . . . . . . . . . . . .

16. Tension of the Masseter and Digastric Muscles Plotted Against High Force Application to the Ipsilateral Canine Tooth. Illustrates Reciprocal Innervation. Cat 12026 . . . . . 50

17. Tension of the Masseter and Digastric Muscles Plotted Against High Force Application to the Ipsilateral Canine Tooth. Cat 12156 . . . . 51

18. Tension of the Masseter and Digastric Muscles Plotted Against High Force Application to the Ipsilateral Canine Tooth. Cat 12156 . . .

19. Tension of the Masseter Muscle Plotted

Against High Force Application to the Ipsilateral Canine Tooth. Cat 11286 . . . .

20. Tension of the Masseter Muscle plotted the High Force Application to the Ipsilateral Canine Tooth. Cat 12106 . . . . . . .

21. Note Initial Decrease in Masseter Tension at High Force Application . . . . . . . . 55

22. Digastric Tension Plotted Against High Force Application to the Ipsilateral Canine Tooth Cat 12106 . . . . . . . . . . . .

23. Digastric Tension Plotted Against High Force Application to the Ipsilateral Canine Tooth Cat 11286 
FIGURE

PAGE

24. Stimulation of the Palatal Gingiva and Comparison of the Muscle Response to Stimulus Intensity Cat 12106 . . . . . . . . . .

25. Note Initial Decrease in Masseter Tension Upon Electrical Stimulation of the Dental pulp . . . . . . . . . . . . . . .

26. Mechanical stimulation within the Maxillary Canine Pulp Chamber Cat 91177 . . . . . . 60

27. Manual Stretch of the Digastric Showing Masseter Relaxation Cat 02067 . . . . .

28. Manual Stretch of the Masseter Showing Digastric Relaxation Cat 02067 . . . . . 


\section{LIST OF TABLES}

TABLE

PAGE

1. The Changes in Tension of the Masseter Muscle for Low Force Application to the Ipsilateral Canine Tooth . . . . . . . .

2. The Changes in Tension of the Digastric Muscle for Low Force Application to the Ipsilateral Canine Tooth . . . . . . . .

3. The Changes in Tension of the Masseter Muscle for High Force Application to the Ipsilateral Canine Tooth . . . . . . . .

4. The Changes in Tension of the Digastric Muscle for High Force Application to the Ipsilateral Canine Tooth . . . . . . .

5. Tensions Developed by the Masseter and Digastric when Varied Electric Potentials of Constant Frequency are Applied to the Palatal Gingiva Cat 12106 . . . . . . . 
CHAPTER I

INTRODUCTION AND STATEMENT OF THE PROBLEM

Mastication involves a number of reflexes. One such reflex of considerable importance is that which is evoked when force application to a tooth causes alterations of tension in the masticatory muscles. The alteration of tensions are not identical in either the synergists or the antagonists. Electromyographic analysis of the muscles has revealed relative changes of tension that occur in each muscle. This analysis has also determined the relationship of these relative changes of tension in each masticatory muscle to its synergist or antagonist. Anatomic studies of the muscles of mastication have arrived at estimations of their contractile potentials. The anatomic studies could not demonstrate the dynamic tensional relationships that occur.

The object of this study is to qualitatively and quantitatively evaluate the contractile tensions developed by antagonistic muscles of mastication when varied force stimuli are applied to the teeth of the cat. 


\section{CHAPTER II}

\section{REVIEW OF THE IITERATURE}

Sherrington (1917) reported that pressure upon the tooth crown gave rise to jaw opening. This opening of the jaw occurred quickly and persisted as long as the stimulus was applied to the tooth. He determined whether the stimulus was unilateral or bilateral by separating the mandible at the symphsis and observing the sections of jaw. while the tooth was stimulated.. A mild stimulus produced a unilateral response whereas a strong stimulus elicited a bilateral response. It should be noted, however, that strong stimulation caused a feeble reaction in the contralateral muscle.

Sherrington stated that these movements were not limited to the decerebrate preparation:

All the above reflexes can be demonstrated easily in the normal, i.e., not decerebrate, animal under various degrees of chloroform or ether narcosis.

Quantitation of the tooth stimulus threshold was reported as early as 1927 by stewart. . He stated that the threshold of $16-32 \mathrm{gm} . / \mathrm{mm} .^{2}$ was not accurate but was to 
serve as a qualitative guide.

With the use of calibrated bristles, Pfaffmann

(1939) determined that a threshold force of $2-3 \mathrm{gm}$. on the canine tooth was necessary to evoke an action potential in the dental nerve. He concluded that touch or pressure applied to the intact tooth gave rise to a diphasic discharge of impulses in the dental nerves. This response to touch or pressure had directional qualities, i.e., a pressure in one direction evoked a response in a particular region within the trigeminal sensory nucleus. Kruger and Michel (1962) plotted the fields in the sensory trigeminal complex activated by tooth stimulation. They compared the precise nature of directional sensitivity of the tooth to that of the vibrissae. This information was also corroborated by Kubota and Kawamura (1964) who applied a pressure stimulus to teeth and recorded activity in the trigeminal sensory nucleus. They found that specific sites in the bulbar and spinal trigeminal nuclei responded to pressure applied to the canine tooth from a specific direction.

The spring esthesiometer was utilized by Loewenstein and Rathkamp (1954) to establish the pressure thresholds of normal and pulpless teeth. This machine enabled them 
to control the stimulation to teeth more accurately than the calibrated bristle method used by Pfaffmann. The spring esthesiometer developed forces from 0 to $14 \mathrm{gm}$. Threshold values reported by this method ranged from $0.5 \mathrm{gm}$. to $5.4 \mathrm{gm}$.

A versatile tooth stimulating machine was introduced by Cuozzo (1966) and Kisior(1966). A torque wrench, the activating element of this machine, developed forces from 0 - $300 \mathrm{gm}$. Additional force to $9000 \mathrm{gm}$. was obtained by adding weights to the tooth stimulating tip. Maximum response, determined electrophysiologically, was recorded when the incisal edge of the tooth was stimulated with force directed parallel to the long axis of the tooth. The threshold force of the mandibular canine was $4 \mathrm{gm}$. Diphasic action potentials were recorded which increased in amplitude as greater increments of force were applied. A leveling off of the responses occurred in the range of $40 \mathrm{gm}$. to $1100 \mathrm{gm}$. of force application. Above $1100 \mathrm{gm}$. , the amplitude increase per unit increment of force again climbed rapidly. Forces exceeding 9000 gm. initiated obvious pain responses. 
Harrison and Corbin (1940) were the first to show action potentials in the mesencephalic root of cats in response to stimulation of the teeth and stretch of the masticatory muscles. This pressure stimulation of the canine tooth caused an action potential in the caudal half of the homolateral mesencephalic root. The canine teeth, contrary to Sherrington's finding, were the most responsive of the oral structures stimulated... Harrison and Corbin (1942) reported that the type jaw movement obtained by a light tap on the tooth varied from animal to animal but the response was constant for a particular animal. The responses were equally divided between jaw opening and jaw closure. Jaw opening was in most instances accomplished by active contraction of the jaw opening muscles, but occasionally by the mere inhibition of the masticatory muscles.

Eisenman, et. al., (1963) also mapped receptive fields to light tooth stimulations within the main sensory trigeminal nucleus and the spinal nucleus of the trigeminal tract. The receptor cells within the periodontal ligament were very sensitive and some responded to the stroke of a soft brush on the tooth. The receptive field 
of the periodontal cells were restricted to the ipsilateral side. This field was often small and confined to one tooth. There was frequently convergence from several teeth from all ipsilateral incisors and molars. Convergence from the maxillary and mandibular teeth was also found.

That sensory information from the dental pressoreceptors is directed to the mesencephalic nucleus was shown by Jerge (1963).

Kawamura et al. (1958) determined the effect upon the mesencephalic and pontine nuclei of elevation and depression of the mandible. These nuclei were inhibited by elevating the jaw and accelerated by depressing the jaw. Kawamura et al. (1959) demonstrated reciprocal. relationships between the responses from antagonistic muscles. The increased activity of the trigeminal motor nucleus which results from stretching the masseter muscle can be inhibited when the homolateral digastric muscle is stretched. Afferent impulses from a jaw muscle will reciprocally inhibit the motor neurons of that muscle's antagonist. There is a summation of responses in the 
trigeminal motor nucleus when synergistic muscles are stretched. The morphologic evidence for this pathway was shown by Szentagothai (1948). He demonstrated that fibers of the mesencephalic tract come-from the annulospiral and flower spray endings of the.. spindles in the muscles of mastication. Before joining the motor root of the trigeminus, these processes give reflex collaterals to the motor ganglion cells of the trigeminal motor nucleus.

Electromyography has afforded a means of studying the role of the functioning muscle of mastication. Moyers (1950) stated that mandibular depression is brought about by contraction of both the external pterygoid and digastric muscles. The digastric muscles participate to a greater extent during the later portion of mandibular opening. The suprahyoid muscles stabilize the mandible during all of its excursions. Elevation of the mandible is accomplished by the integrated contractions of the internal pterygoid, masseter, and temporalis muscles. The middle and posterior fibers of the temporalis muscle effect the retraction of the mandible. 
Pruzansky (1952) observed that the direction of pull exerted by the posterior fibers of the temporal muscle is antagonistic to that of the external pterygoid muscle. The activity of the masseter muscles decreased when the canine teeth occluded.

A mechanical and an electromyographic analysis of the movements of the muscles of mastication was performed by Carlsoo (1952). The elevator muscles had favorable moment arms for closing movements of the jaw. He listed the muscles with the greatest to the smallest moment arms as follows: superficial masseter, anterior half of temporalis, deep masseter, medial pterygoid, and posterior half of the temporalis.

The electromyographic analysis revealed the temporalis muscle to be the primary muscle engaged in a habitual closing movement and maintaining the postural position of the mandible at rest position. From a functional standpoint, this muscle can be divided into two parts: an anterior and a posterior portion. The anterior portion is more active in mandibular rotation while the posterior portion is more effective in 
translation. The masseter was more active than the temporalis muscle in cutting movements of the mandible. In comparing the mechanical qualifications of muscles to their functional characteristics, Carlsoo concluded:

The distribution of the muscular activity cannot be deduced from a knowledge of the mechanical qualifications only, nor according to the principle of reciprocal innervation alone.

MacDougall and Andrew (1953) demonstrated that the entire masseter and the anterior fibers of the temporalis were engaged when the incisor teeth were placed in an end to end relationship. Activity was equally spread over the masseter and temporalis when the molar teeth were in occlusion. Normal background. activity was recorded over the masseter and temporalis during unforced mouth opening. The suprahyoid group also registered the basic resting value over the greater part of the unforced mouth opening. Attempted opening of the mouth against resistance was accompanied by activity over the supra and infra hyoid muscles. 
Tulley (1953) observed forceable contraction of the masseter during swallowing.

An electromyographic study of the temporalis and masseter muscles from Jarabak (1954) concluded that elevation of the mandible was accomplished principally by the temporalis. The masseter contributed strength to the masticatory stroke.

A variation to this theme was offered by Perry and Harris (1954) who observed the temporalis moved the mandible to a functional position. The masseter then complemented the action of the temporalis until centric occlusion was accomplished.

Vaughan (1955) stated that the opening act of the mandible is a tilting act performed by the external pterygoid and suprahyoid muscles. The primary power is supplied by the suprahyoid musculature. The external pterygoids were expendable for the performance of the opening tilt.

Carlsoo (1954) described two variations to the typical reciprocal pattern of the masseter and digastric muscles. Electromyographic activity in the elevator muscles disappeared when the mandible moved from centric 
occlusion to centric relation. The masseter remained inactive if the mandible was slowly opened in its habitual path. Activity in the digastric gradually increased from centric relation to the fully opened position. If the mandibular path of closure was anterior to the habitual path, the masseter activity diminished as opening was accomplished. Activity in the digastrics gradually increased in the anterior position of mandibular closure. Closure of the mandible through the anterior path demonstrated a great activity throughout the range of movement of the digastric muscle.

When the mandible is raised through the habitual path the temporalis muscle is primarily activated while the masseter acts secondarily. These muscles are activated in reverse order if the path of closure is anterior to the habitual path of closure.

In a study of the temporalis and masseter muscles, Greenfield and Wyke (1956) have shown that the anterior and posterior portion of the temporalis muscle is most active in centric, retruded, and ipsilateral molar occlusion. In simple protrusion the anterior portion of 
the muscle displays only background electrical activity. The posterior portion of the temporalis demonstrates some activity in retrusion and ipsilateral movement of the mandible. The lower anterior portion of the masseter. muscle shows the most activity in centric and protrusive occlusion, contralateral molar and incisor biting, and during protrusion of the mandible. The upper posterior portion of the masseter muscle is most active in retrusive and ipsilateral molar occlusion.

Hickey (1957) concluded that the suprahyoid muscles function in a dual capacity, aiding in both opening and stabilizing the mandible.

The work of previous writers concerning the temporalis has been supported by Latif (1957). The temporalis retracts the protruded jaw but is not involved in mandibular protraction. In the act of incision, the anterior fibers are more active. The temporalis is active in elevating the mandible with all fibers active during molar occlusion. This muscle maintains mandibular posture in centric relation primarily through activity of the posterior fibers. 
13

Schaerer and Stallard (1965) note the contraction of the mandibular elevators can be divided in isotonic and isometric phases. The isotonic phase is associated with free mandibular movement while the isolmetric phase is related to the period of centric occlusion. They demonstrated the variability in mascle activity due to varying recruitment of motor units during all phases of muscle contraction in mastication. 
CHAPTER III

METHODS AND MATERIALS

Eleven adult cats were subject to the following laboratory procedures; administration of anesthetic, surgical exposure of masseter and digastric muscles, stabilization, and force application to a maxillary canine tooth. The resulting data was recorded by a physiograph.

Anesthetic Administration

In this investigation the depth of anesthia played an important role. Maximal muscle response to tooth stimulation was obtained by miminal cortical depression by the anesthetic agent. Inhalation anesthesia provided good control of the level of anesthesia and its depth could be readily altered. Ether was the selected anesthetic because it has a high safety factor, it is a respiratory stimulant, and does not depress circulation at the levels employed in anesthesia.

A nose cone was constructed from a glass funnel by inserting a small amount of cotton into the neck 
and tube. The cotton was saturated with ether and the cone cupped about the animal's nose. A towel wrapped about the cat's head and the mouth of the funnel increased the concentration of ether in the inspired air. Depth of anethesia was monitored by observation of the rate and depth of respiration as well as the amount of pupillary dilation. . When the surgical plane of anesthesia was reached, the animal's head and neck, were. shaved. A skin incision made in the midline extended from the superior border of the sternum to a point $2 \mathrm{~cm}$. inferior to the mandibular symphysis. The infrahoid muscles were separated to expose the trachea. A tracheal incision was made $2 \mathrm{~cm}$. inferior to the thyroid cartilage. This incision extended between and parallel to the cartilaginous rings and penetrated the anterior two-thirds of the trachea. A cannula was inserted and ligated. The nose cone was then replaced by a modification of the Ayre's T-tube open anethesia system which allowed. a means of regulating the concentration of the ether and a system for artificial respiration (Eigure 1).. Air and volatilized ether were delivered to respective legs of 


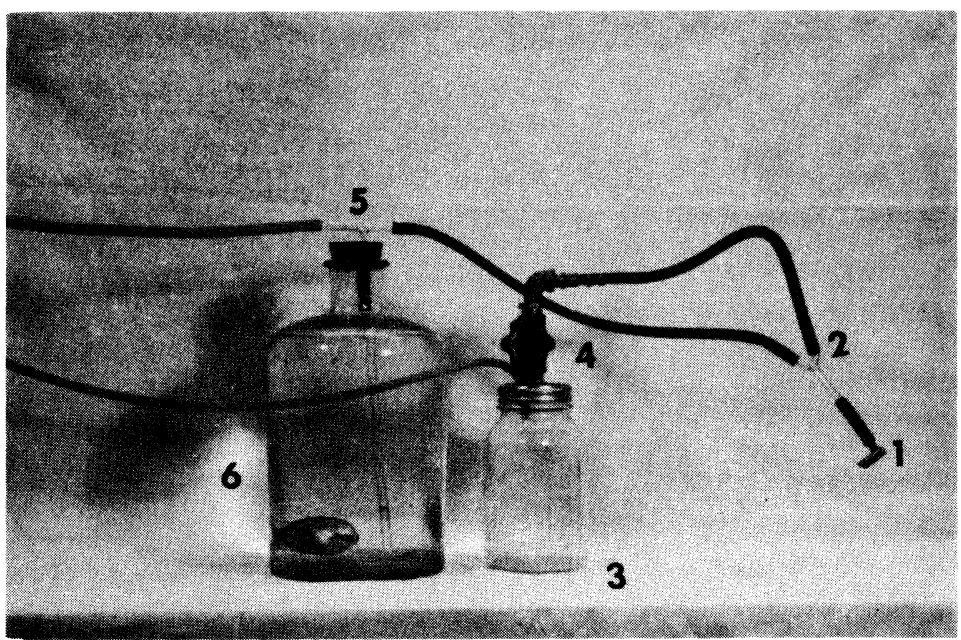

FIGURE 1

ANESTHESIA SYSTEM

1. Tracheal catheter

2. Ayre's T tube

3. Ether jar

4. Control valve

5. GIass T

6. 5 liter water vessel 
the Ayre's T-tube. They then mixed within the stem and were passed on to the trachea through a cannula.

One leg of the Ayre's T-tube was joined to a valved outlet of a closed one liter ether jar by a $9 \mathrm{~mm}$. diameter rubber tubing. The valve controlled the amount of volatized ether to be administered. A slight positive pressure was maintained in the ether jar by connecting it to the compressed air line with a $5 \mathrm{~mm}$. diameter rubber tube.

The pressure within the air system was not to exceed $20 \mathrm{~cm}$. of water in order to maintain the integrity of the lung alveoli. This was accomplished by inserting a glass $T$ into a two-holed rubber stopper which was then pressed into the mouth of a five liter vessel. The stem of the glass $T$ extended $20 \mathrm{~cm}$. into the water within the vessel. Rubber tubing connected one leg of the glass $T$ to the compressed air source and the other leg to the remaining outlet of the Ayre's tube. A $5 \mathrm{~mm}$. hole in the tubing $2 \mathrm{~cm}$. from the Ayre!s tube provided an escape for the animal's exhaled air and/or the compressed air used to inflate the lungs. By occluding this opening the 
pressure in the system could be made to increase and dis place the $20 \mathrm{~cm}$. column of water in the stem of the glass T. Excess air pressure caused the air to bubble through the water and escape out the second hole in the rubber stopper. Thus the pressure of the air to inflate the lungs during artificial respiration did not exceed $20 \mathrm{~cm}$. of water. Synchronization of artificial respiration and the animal's own respiratory efforts was easily accomplished by alternately opening and closing the $5 \mathrm{~mm}$. hole in the tubing to the Ayre's tube.

Surgical Exposure of the Masseter and Digastric Muscles

Dissection of the skin from the superficial muscle layers on one side of the midline incision exposed the external jugular vein. The mandibular reflection of the skin ended $2 \mathrm{~cm}$. from the mandibular symphysis and laterally to the junction of buccal mucosa and skin. The platysma muscle and body of the mandible were visible. Continued lateral reflection $r \in$ moved the skin over the corner of the mouth to the zygomatic arch baring the masseter muscle. The masseter was detached from the anterior two-thirds of the zygomatic arch. Separation of the masseter from 
contiguous structures along intervening fascial planes reduced the mechanical connection between this muscle and the digastric muscle.

The attachment of the playsma muscle to the anterior portion of the mandible was severed and the muscle stripped back to a line $3 \mathrm{~cm}$. inferior to the hyoid bone: Dissection of the digastric muscle along its fascial sheath permitted it to be isolated from the adjacent musculature. Elevation of the digastric from the mandibular body accomplished detachment of its anterior end from the animal. An attempt was made to maintain the blood and nerve supply but the fascial attachments were removed.

Six to ten ml. of Dextran, a glucose polysaccharide, were injected in the external jugular vein. The injection of Dextran, $6 \%$ normal saline, countered the effects of hemorrhage and traumatic shock.

The masseter and digastric muscles were periodically moistened with Tyrode's solution heated to $37^{\circ} \mathrm{C}$., thereby extending the physiologic integrity of the tissue and prolonging muscle activity. The Tyrode's solution 
was made in the following manner: $8.00 \mathrm{gm}$. sodium chloride, $0.20 \mathrm{gm}$. potassium chloride, $0.20 \mathrm{gm}$. anhydrous calcium chloride, $1.00 \mathrm{gm}$. sodium bicarbonate, $0.10 \mathrm{gm}$. magnesium chloride, and $0.05 \mathrm{gm}$. dibasic sodium phosphate added to sufficient distilled water to make one liter of solution. Prior to use, $0.10 \mathrm{gm}$. of glucose was mixed with $100 \mathrm{ml}$. of the solution.

Stabilization

The accuracy of the data obtained from this experiment was directly proportional to the immobility of the animal's head. It was felt that the stereotaxic device to be described achieved complete fixation of the maxilla, mandible and upper neck (Figure 2).

The animal was placed in a supine position upon the stereotaxic device. The body section was made from a $\frac{1}{2}$ in. $x 12$ in. $x 18$ in. piece of polyvinyl chloride. Eight slots were milled into the base to accept restraining straps. A section of $\frac{1}{2}$ in. $x 5$ in. $x 5$ in. polyvinyl chloride extended from the 12 in. width. The head section was centered with the 12 in. dimension of the body section and supported the head and neck holding 


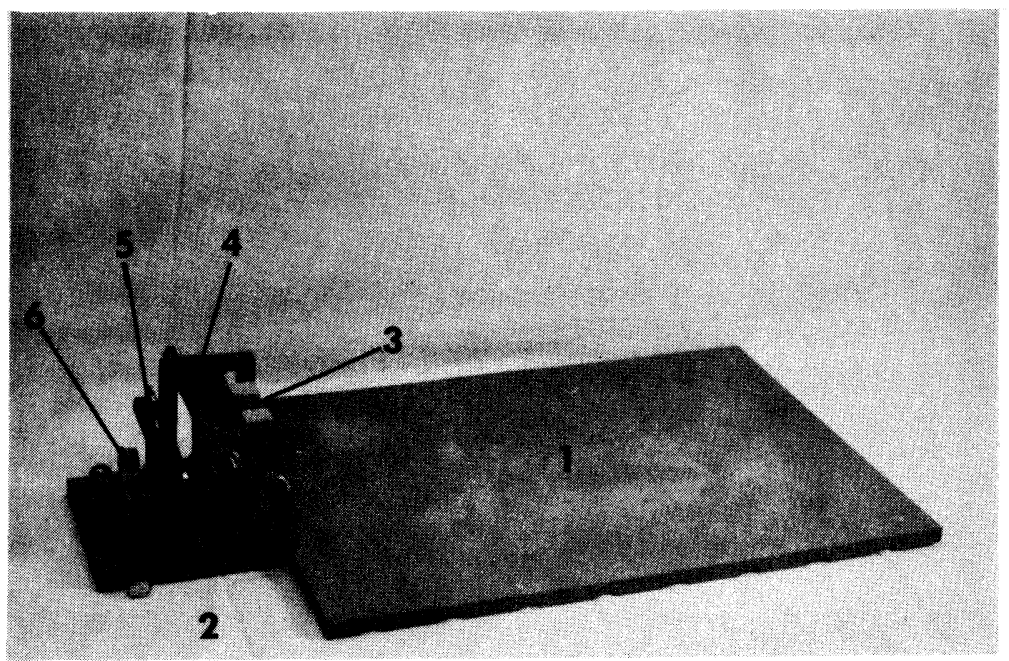

FIGURE 2

STEREOTAXIC DEVICE

1. Body section

2. Head section

3. Neck yokes

4. Mand1bular bar

5. Palatal bar

6. Muzzle support 
elements.

The neck was fixed by two yokes placed on its lateral aspect. Each yoke was attached to a $\frac{1}{2}$ in. threaded bar which passed through vertical slots into the first pair of lateral supports. The $3 \frac{1}{2}$ in. lateral supports which rose perpendicular to the head section, had a $5 / 8$ in. slot running vertically. These slots allowed vertical positioning of the neck. Nuts on either side of the lateral supports adjusted the firmness of the yokes about the neck and fixed its vertical heights.

A second pair of lateral supports identical to the first was placed adjacent to the edge of the head section adjoining the yoke holding lateral supports. A $\frac{1}{2}$ in. bar threaded at the ends passed through the vertical slots of the lateral supports. Nuts screwed medial and lateral to the supports permitted adjustment and fixation of the bar. The mandible was fixed by tying it to the bar.

A curved $\frac{1}{2}$ in. $x 1 \frac{1}{2}$ in. $x 2 \frac{1}{2}$ in. piece of wood centered on the head section 1 in. from the ends of the lateral mandibular support served as the muzzle support. 
The muzzle support was contoured to accommodate various head size differences. The maxillary canine teeth were situated over the support to achieve stability when forces were applied to them.

A section of $5 / 8$ in. $x 5$ in. tempered aluminum U-shaped channeling held the maxilla to the head section. The channeling, the palatal bar, engaged the posterior cusps of the first molar teeth and was placed between and parallel to the muzzle support and the mandibular bar. Screws extended through the head section via countersunk slots and then into holes drilled into the ends of the palatal bar. Wing nuts on the screws pressed the palatal bar upon the maxilla and thereby prevented its movement.

C-clamps secured the stereotaxic device to the work surface.

Force Application

Two instruments were used to exert controlled forces upon the maxillary canine tooth. A torque system was employed to produce forces from $100 \mathrm{gm}$. to $1500 \mathrm{gm}$. , 
while a hydraulic system was used to exert forces of $1 \mathrm{kgm}$. to $23 \mathrm{kgm}$. Utilization of both methods provided accurate force application by not overextending the mechanical limitations of either system.

The torque instrument was designed and constructed by the P.A. Sturtevant Company of Addison, Illinois (Figure 3). The torque wrench, a common tool in industry, forms the basis of this machine: (Figures 4,5 ). The essential parts of the torque wrench are the metal beam, drive head, and calibrated scale. Within the working range of the tool, a linear relationship exists between the force applied to the beam and its deflection. The amount of deflection is measured on a scale which is calibrated in gram-inches of torque force. This force is developed one inch from the axis of the drive head. In this experiment, the force was applied 12 inches from the axis of the drive head. Consequently, the force developed by the torque wrench was reduced by a factor of twelve and the scale on the wrench was calibrated to this lever arm distance. This permitted the arc described by the movement of the shaft's end to be more linear 


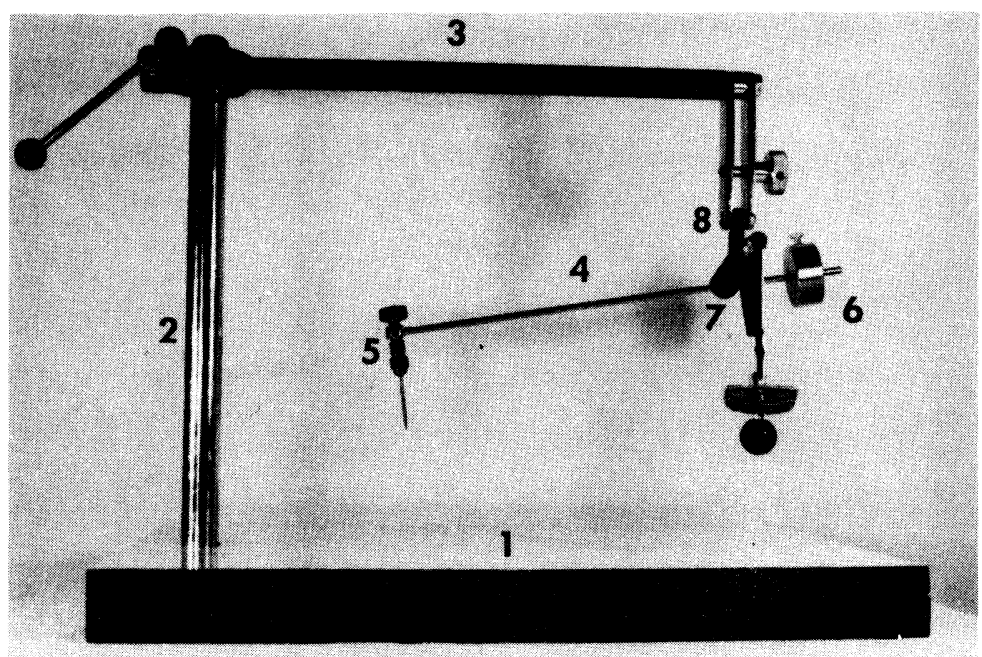

FIGURE 3

TORQUE INSTRUMENT

1. Metal base

2. Vertical post

3. Adjustable horizontal arm

4. Shaft

5. Chuck-pointer assembly

6. Counter-balance welght

7. Axle assembly

8. Ball and socket joint 


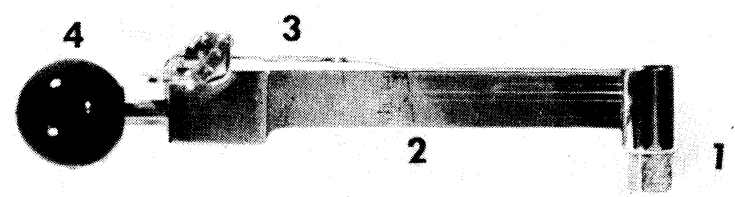

FIQURE 4

TORQUE WRENCH (SIde vlew)

1. Drive head

2. Metal beam

3. Pointer shaft

4. Handle 


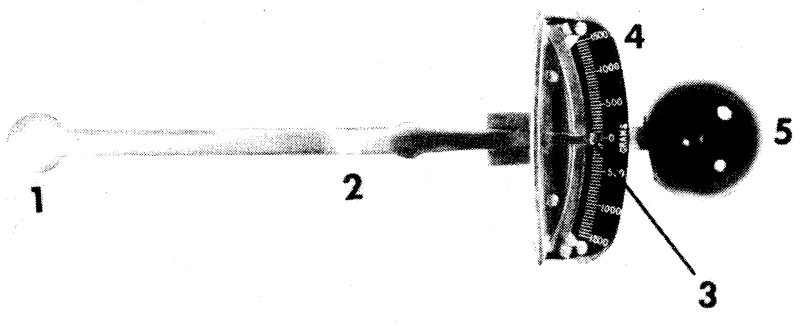

FIGURE 5

TORQUE WRENCH (TOP vieW)

1. Drive head

2. Metal beam

3. Pointer

4. Callprated scale

5. Handle 
so that the line of force application would nearly be parallel to the long axis of the tooth. A chuck and metal pointer at the shaft's end allowed for alignment of the pointer to the tooth. A counter-balance weight cancelled the effect of the weights of the shaft and chuck-pointer assembly upon the tooth. The counterbalance was adjusted prior to each experiment to place the shaft, chuck-pointer assembly, and torque wrench in equilibrium.

The axle assembly joined the torque wrench to the shaft. Ball bearings minimized the friction within the axle assembly so that most of the torque force developed by the wrench was delivered to the tooth. The axle assembly attached to the supportive fixture via a ball and socket joint.

The supportive fixture was comprised of the following elements: 18 in. $x 28$ in. steel.base, 22 in. vertical post, 26 in. adjustable horizontal arm, and twin bars which grasped the ball of the axle assembly. The vertical post rose from the center of the 18 in. dimension end of the steel base. The horizontal arm which attached 
to the vertical post could be raised, lowered, or rotated about the post. The twin bars were attached at the other end of the horizontal arm. A 5/8 in. bushing between the bars held them apart. This separation accommodated the ball of the axle assembly. A screw interposed between the ball and bushing allowed the bars to tighten about the ball and fix its position. The numerous adjustable parts of the supportive fixture allowed great versatility in the positioning of the chuck-pointer tip. Mechanical limitations of this torque system prevented it from producing forces beyond $1.5 \mathrm{kgm}$. To overcome this limitation, the hydraulic system was developed (Figure 6): This system yielded an effective range of $1.0 \mathrm{kgm}$. to $27 \mathrm{kgm}$. Force magnitudes above these maximums sustained physiologic harm to the preparation rendering it useless.

The hydraulic system offered an accurate method of developing forces with few moving parts which could be easily integrated with the existing torque machine. Parts from an automotive hydraulic braking system were adapted to develop this instrument. A brake pedal 


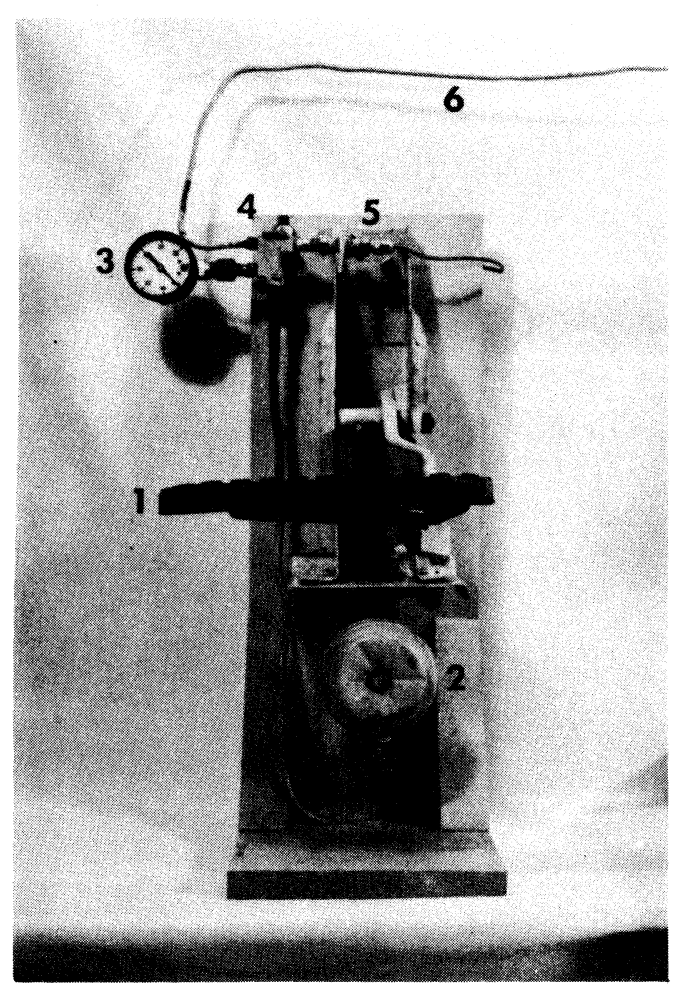

FIGURE 6

HYDRAULIC INSTRUMENT

1. Pedal assembly

2. Master cylinder

3. Fluid gauge

4. Junction box

5. Bleeder valve

6. Hydraulic line to wheel cylinder 


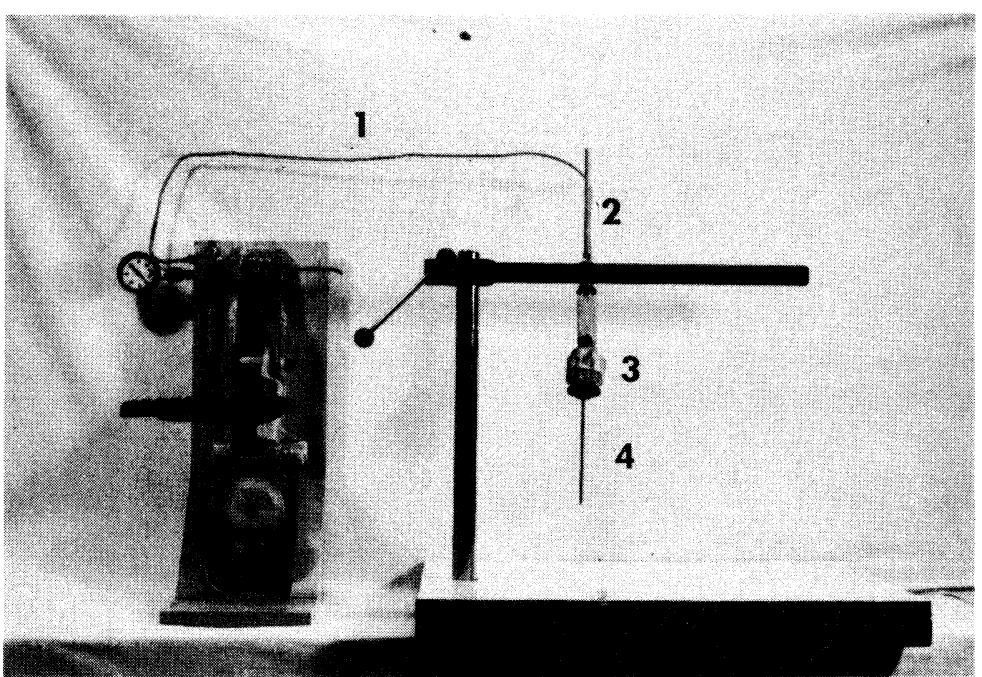

FIGURE 7

COMBINED UTILIZATION OF TORQUE AND HYDRAULIC SYSTEMS

1. Hydraulic line

2. Adjustable rod

3. Wheel cylinder

4. Tooth stimulator rod 
stimulator rod fabricated from $3 / 16$ in. $x$ in. drill rod was attached to the piston... The countersunk end of the rod prevented its dislodgement from the end of the tooth.

Transducers and Physiograph.

The transducers, physiograph, and electrical stimulation apparatus to be described were manufactured by the E \& H Instrument Company: Inc., 6030 England Street, Houston, Texas 77021. Two myographs, a photoelectric force transducer for the quantitative measurement of skeletal muscle contraction, were attached with nylon threads to the free ends of the digastric and masseter muscles (Figure 8). Myographs of differing sensitivities were employed to detect contractile forces produced by the two muscles.

Specification of myographs Digastric Masseter

Maximum sensitivity (gm/cm of physiograph pen deflection)

Maximum range (grams)

$0-3.0$ $0-30.0$

Displacement (mm./gm)

0.8

0.08 


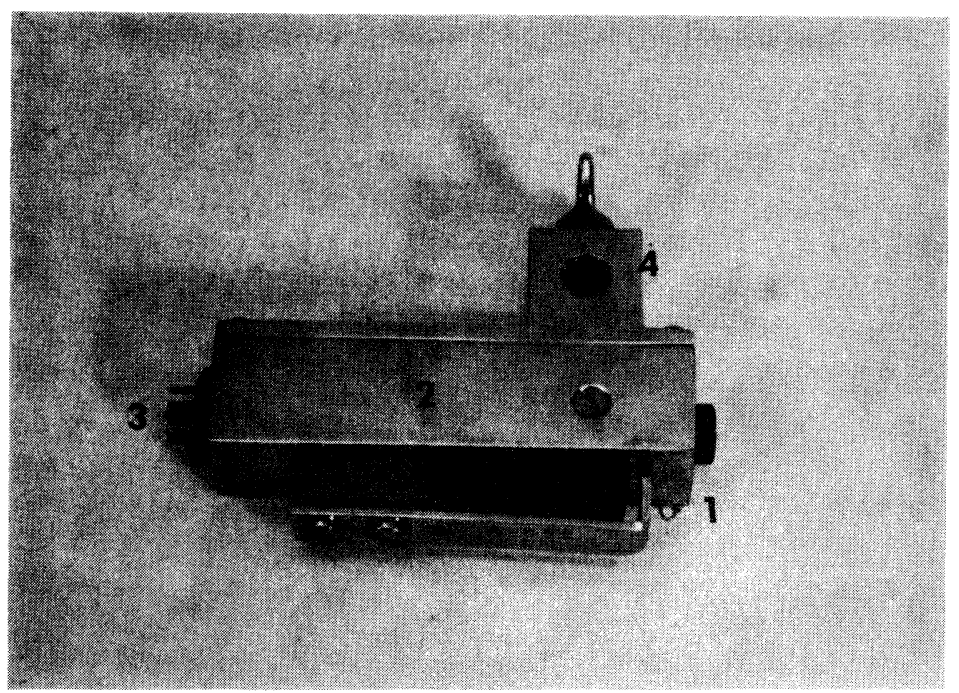

FIGURE 8

MYOGRAPHS

1. Hook attachment for muscle thread

2. Photoelectric unit housing

3. Phys lograph cable plus

4. Mounting hole 
The outputs of the myographs were fed to separate amplifiers in the physiograph. The amplifiers provided the required increases in signal strengths, while maintaining the proportional relationships of the electrical signals and the physiological activities which it represents. The outputs of the amplifiers were connected to the pen recorder.

The pen recorder consists of a pen motor, an electrically driven stylus, an inking system and a moving paper chart (Figure 9). The paper speed was maintained at $1 \mathrm{~cm}$. per second throughout this experiment. The excursions of the pen across the moving chart are proportional to the physiological activity and provide a permanent record of the experiment.

The Physiograph Four main frame assembly is a basic four channel housing for the installation of recording channels and accessory plug-in modules; it also provided power distribution, control, and monitoring circuits. Six compartments were provided for plug-in modules: four for amplifiers or accessories; two for the paper control unit and an additional accessory plugin module. This system provides facilities for these 


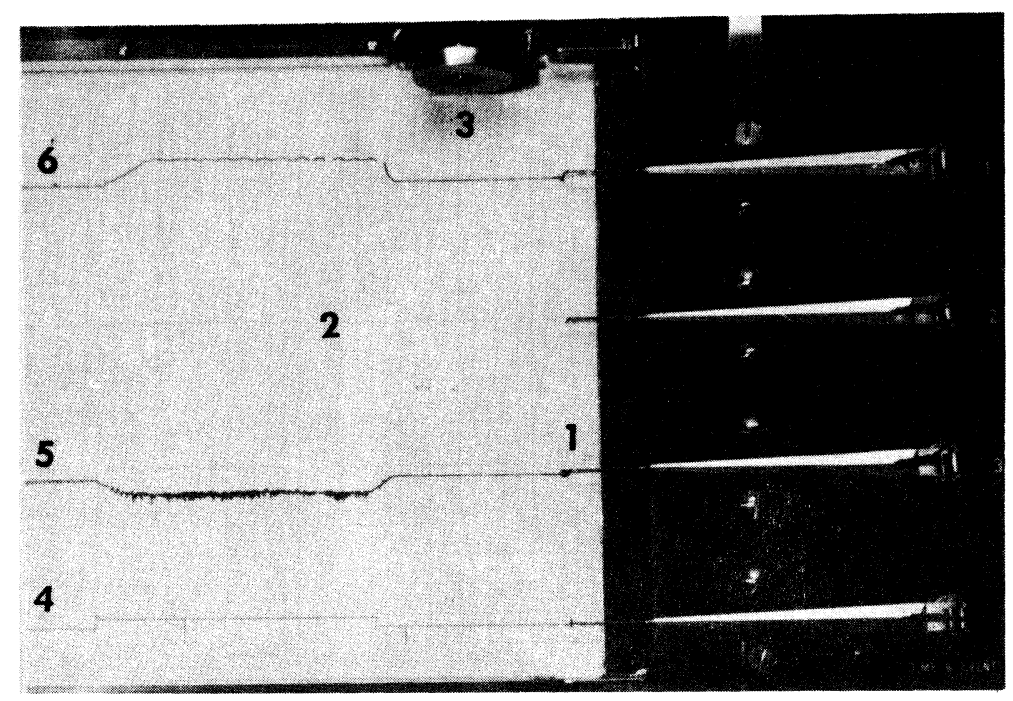

FIGURE 9

PEN RECORDER SECTION OF PHYSIOGRAPH

1. Electrically ariven stylus

2. Moving paper chart

3. Drive wheel

4. Time - event channel

5. Digastric recording channel

6. Masseter recording channel 
recording channels and a time-event channel. The paper control unit provides time signals every $1,5,30$ or 60 seconds which are recorded as a momentary downward deflection of the time-event pen. The time-event channel pen deflects upward when actuated by the panel mounted event marker push button switch, the stimulator accessory plug-in module, or from an external marker jack.

The stimulator was used to apply Faradic potentials upon the palatal gingiva, tooth, and tooth pulp chamber. The amplitude of the square wave output pulses were continuously variable from 0 - 130 volts. Pulse duration could be adjusted to $0.1,0.5$, or 2.0 milliseconds. The pulse repetition frequency was continuously variable from 2 - 200 pulses per second. But in this experiment, the range of pulse frequencies was limited from 3 to 50 pulses per second.

The animal lay in the supine position within the stereotaxic device. The opened mandible presented good access to the maxillary canine tooth. The stereotaxic device was clamped to the base of the torque machine so that the arc of movement of the chuck-pointer assembly 
coincided with the incisal edge of the maxillary canine tooth. Force increments of $100 \mathrm{gm}$. were applied to the tooth until the maximum torque machine output of $1500 \mathrm{gm}$. was attained. The marker pen was activated to indicate the onset, termination, and span of force application. The average duration of force application was 10 seconds. The hydraulic machine applied forces from 1.1 $\mathrm{kgm}$. to $23 \mathrm{kgm}$. in $0.9 \mathrm{kgm}$. increments. The durations of force application averaged 11 seconds. All residual forces were removed from the tooth between periods of force application. A second series of forces, identical to the first, were applied with the exception that the force increments were additive and thus the tooth experienced forces throughout the series.

Electrical stimuli were applied to the palatal gingiva, tooth enamel, dentin, and tooth pulp chamber. The frequencies of the stimuli employed were $5,10,25$, and 50 pulses per second. The stimuli intensities were $3,5,10,25$ and 50 volts. The stimulation was held at a given frequency and the intensity of the stimulus varied at each of the voltages mentioned. Successive 
changes in frequencies and the concomitant change of intensities provided a wide range of reflex muscle response. 


\section{CHAPTER IV}

\section{FINDINGS}

The forces in this investigation are arbitrarily categorized as either of low magnitude or of high magnitude. The forces from $100 \mathrm{gm}$. to $1500 \mathrm{gm}$. are referred to as low forces while those from $1.5 \mathrm{kgm}$. to $23 \mathrm{kgm}$. are termed high forces.

The masseter displayed an increase in monitored tension in five preparations when low forces were applied to the maxillary canine tooth (Figures 10-13). The threshold force for this reflex contraction ranged from $500 \mathrm{gm}$. to $1000 \mathrm{gm}$. with a mean value of $580 \mathrm{gm}$. (Table 1). The contractile forces developed at individual thresholds ranged from $0.07 \mathrm{gm}$. to $0.48 \mathrm{gm}$. with $0.21 \mathrm{gm}$. the mean force. At $1500 \mathrm{gm}$. the contractile tensions ranged from $0.25 \mathrm{gm}$. to $2.65 \mathrm{gm}$. with the mean of $0.95 \mathrm{gm}$.

A reduction in tension for the digastric occurred in six cats when low forces were applied (Figures 10-12, 14, 15). The proprioceptive threshold for this reflex relaxation varied from $200 \mathrm{gm}$. to $900 \mathrm{gm}$. with a mean 
threshold value of $517 \mathrm{gm}$. The detectable force application threshold for this reduction in tension varied from $0.002 \mathrm{gm}$. to $0.053 \mathrm{gm}$. with a mean reduction of $0.026 \mathrm{gm}$. (Table 2). At $1500 \mathrm{gm}$. the change in tensions compared to pre-force application varied from $-0.010 \mathrm{gm}$. to $-0.182 \mathrm{gm}$. with the mean of -0.028 .

The graphs display a decrease in digastric tension as the force is increased (Figures 10-12, 14). Cat 12156, however, experienced a period of increasing digastric tension from 1,100 gm. to 1,500 gm. (Figure 15). There was no direct and consistent relationship between an increment of applied force and a change in muscle tension.

A reciprocal relationship between the masseter and digastric muscles to low force magnitudes was clearly demonstrated in three preparations (Figures 10-12).

Five preparations demonstrated the continued contraction of the masseter at high forces (Figure 1620). Table 3 represents the data for changes in tension of these graphs. At any given force application, a wide disparity existed between the changes in tension observed 
for individual cats. A given force increment does not proportionally increase the tension development of the muscle.

An interesting contraction pattern was observed in the masseter at high forces... In two preparations a significant decrease in masseter tension occurred just prior to its contraction. This decrease in tension was of short duration when compared to the longer period of increased tension (Figure 21).

In three preparations, the digastric muscle continued to exhibit a reduction in tension at high forces during a portion of the force application range. In two of these three preparations, the digastric muscle showed a positive increase in tension for the lower forces. However, in the third animal, the tension was always less than the control although the amount of reduction declined (Figures 16-18). An increase in digastric tension development without previous reduction at lower forces for this range (1.5 kgm. to $23 \mathrm{kgm}$.) occurred in two preparations (Figures 22,23 ). Table 4 presents the data used to plot the digastric muscle tension 
against force application.

The palatal gingiva was stimulated with electrical currents whose potentials varied from three volts to 25 volts. Figure 24 demonstrates progressive reduction in masseter tension development and progressive increase in digastric tension development as the stimulation potential is increased from five volts to 25 volts. An example of the tensions developed by these muscles is shown in Table 5 .

The masseter exhibited a decrease in tension development followed immediately by a long term tension increase in two instances of electrical stimulation of the canine pulp chamber (Figure 25).

Mechanical stimulation of the maxillary canine pulp chamber evoked decreased masseter tension while increasing digastric tension (Figure 26).

Manual traction upon the digastric muscle caused a decrease in tension development by the masseter muscle (Figure 27). A similar reduction in tension was observed for the digastric when traction was placed on the masseter (Figure 28). 


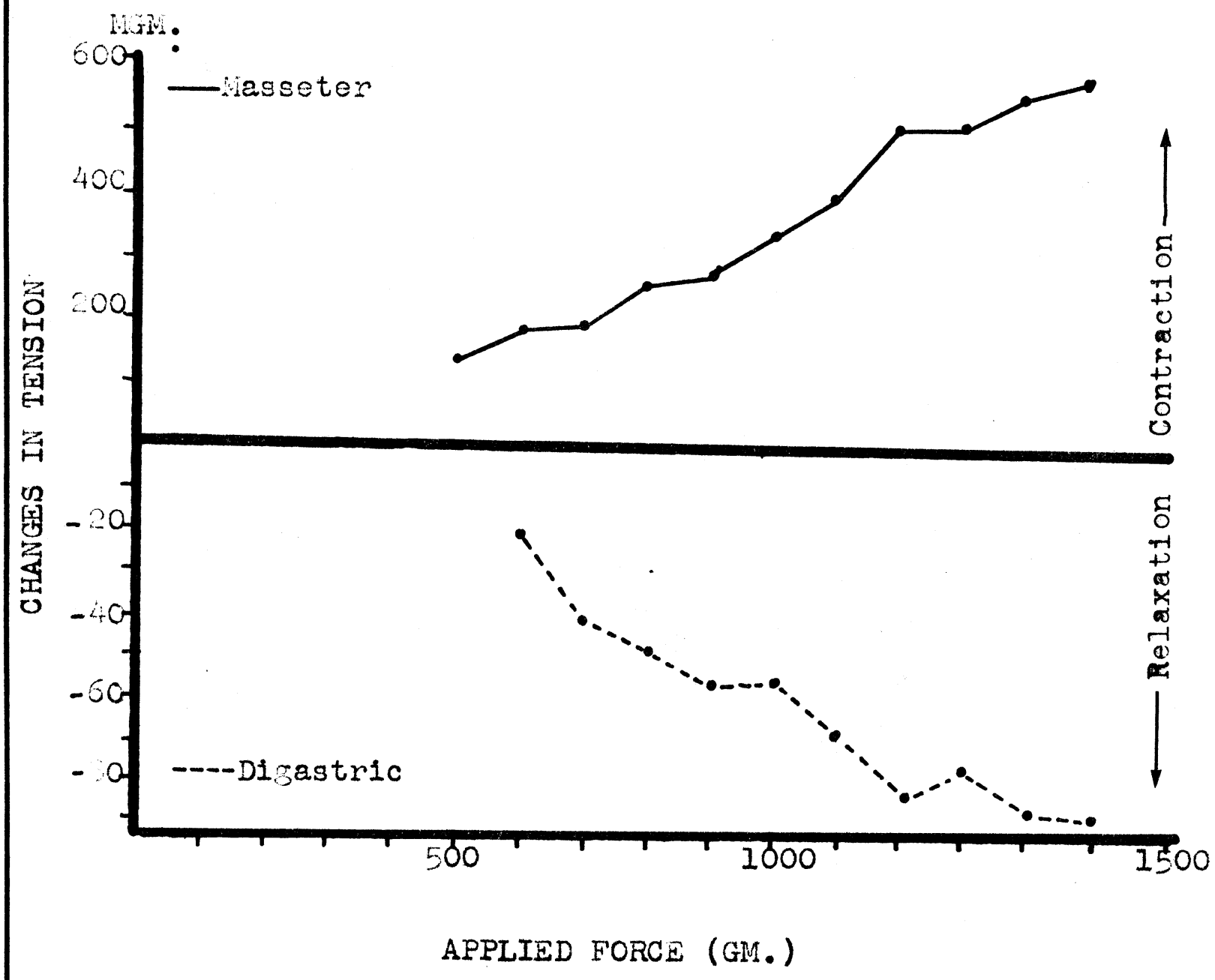

FIGURE 10

TENSION OF THE MASSETER AND DIGASTRIC MUSCLES PLOTTED

ACAINST LON FORCE APPLICATION TO THE IPSILATERAL CANINE

TOONH. ILLUSTRATES RECIPROCAL INNERVATION. CAT 00306. 


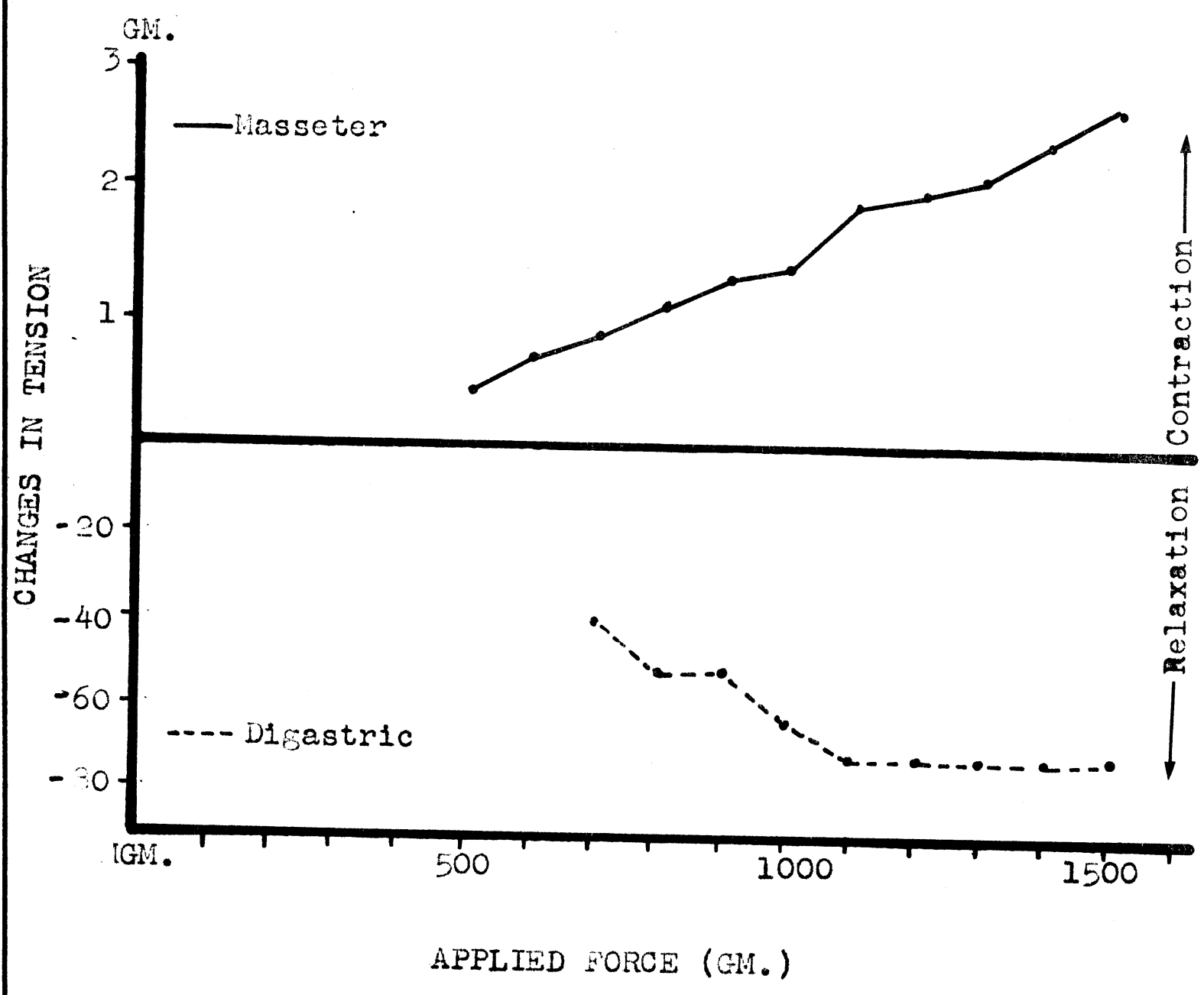

FIGURE 11

TENSION OF THE MASSETER AND DIGASTRIC MUSCLES PLOTTED ACAINST LOH FORCE APPLICATION TO THE IPSILATERAL CANINE TOOTH. ILLUSTRATES RECIPROCAL INNERVATION. CAT 11116. 


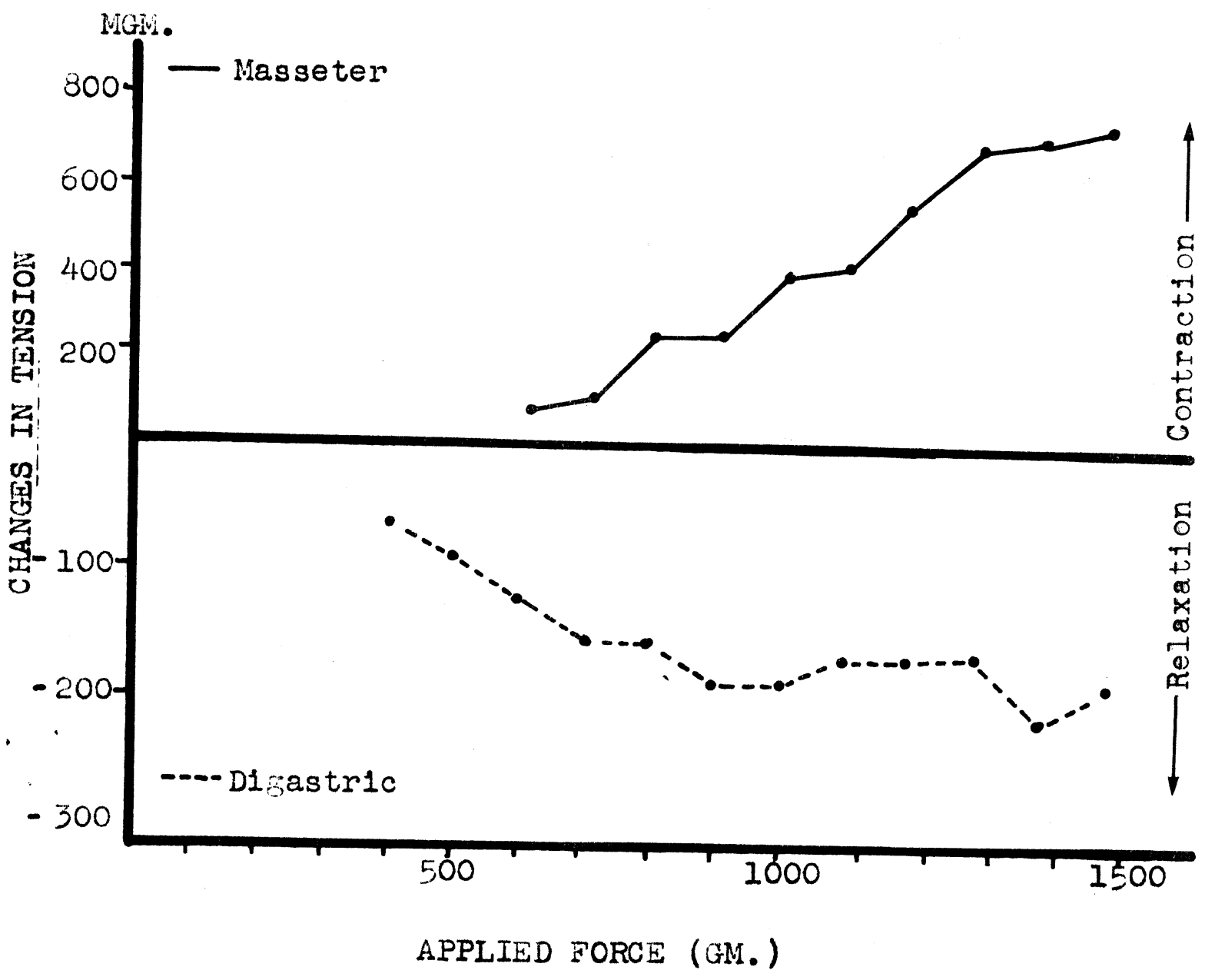

FIGURE 12

TENSION OF THE MASSETER AND DIGASTRIC MUSCLES PLOTTED AGAINST LOW FORCE APPLICATION TO THE IPSILATERAL CANINE TOOTH. IILUSTRATES RECIPROCAL INIERVATION. CAT 11146 . 


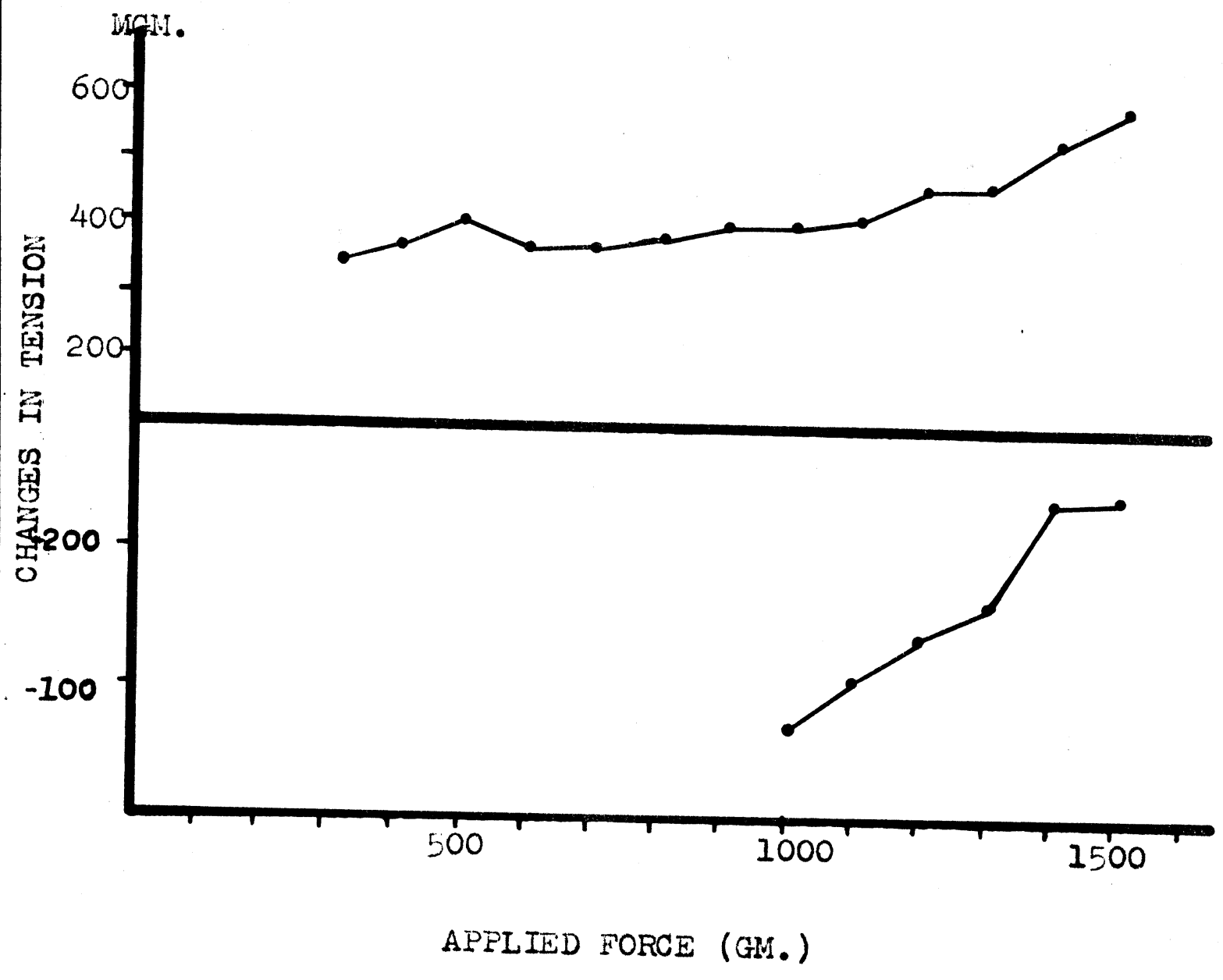

\section{FIGURE 13}

TENSION OF MASSETER MUSCLE PLOTTED AGAINST LOW FORCE APPLICATION TO THE IPSILATERAL CANINE TOOTH. CATS

$$
\text { 12026, } 01137
$$




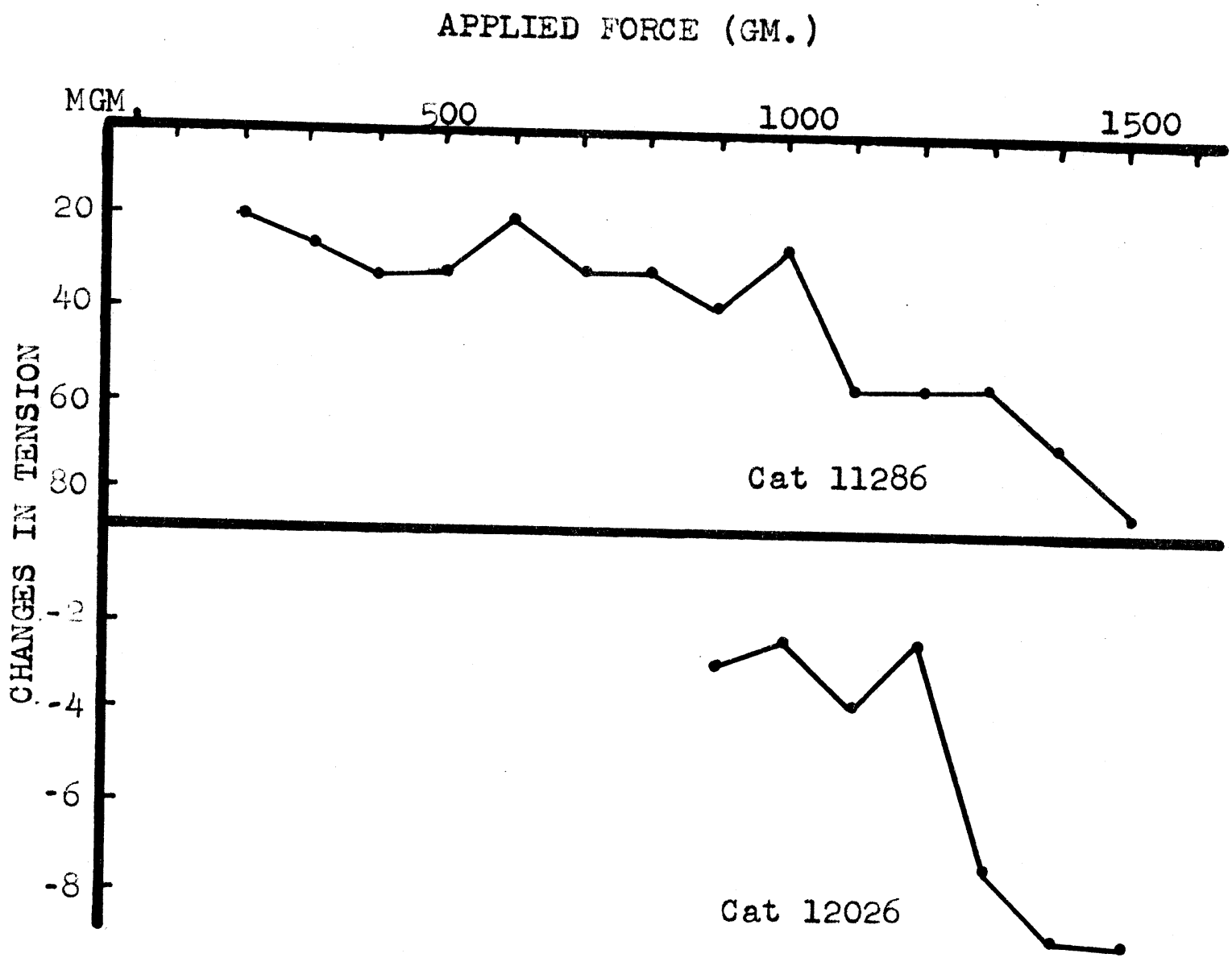

FIGURE 14

DIGASTRIC TENSION PLOTTED AGAINST LOW FORCE APPLICATION TO THE IPSILATERAL CANIIE TOOTH. CATS 11286, 12026. 


\section{APPLIED FORCE (GM.)}

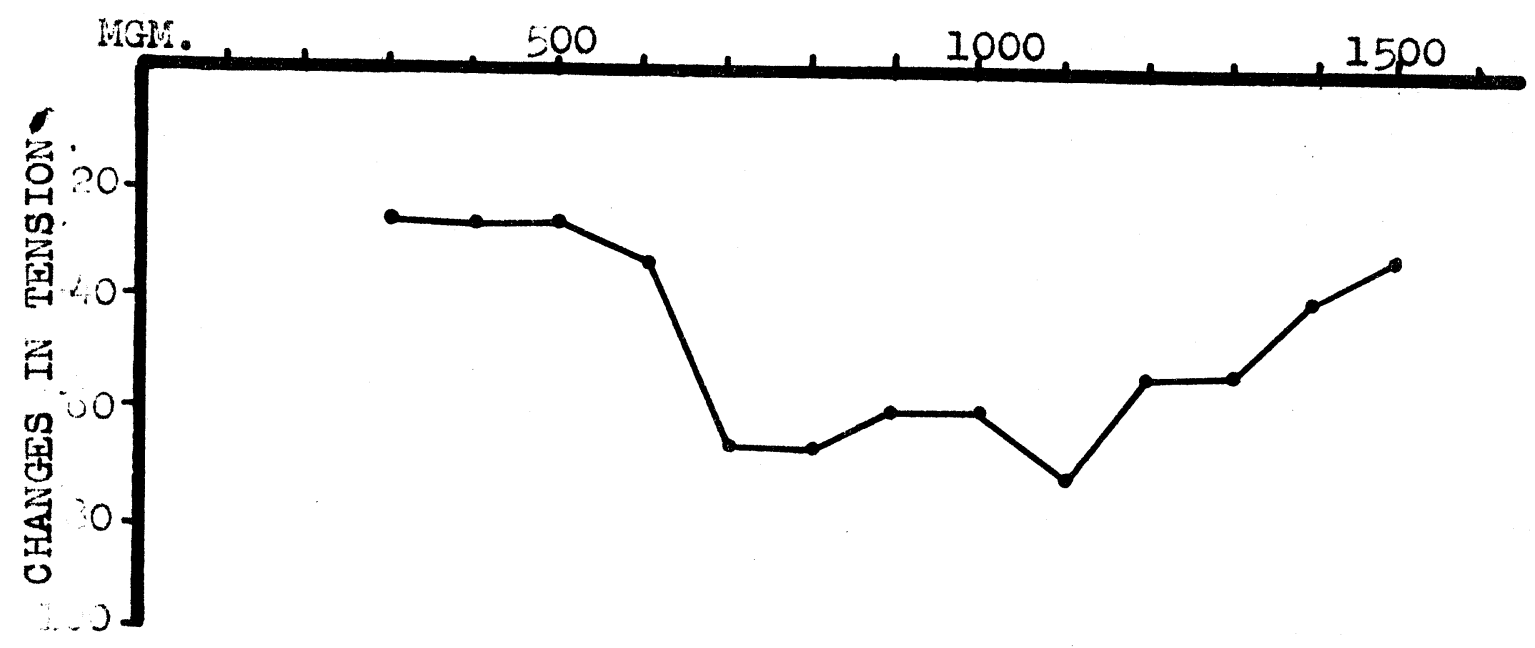

\section{FIGURE 15}

DIGASTRIC TENSION PLOTTED AGAINST LOW FORCE APPLICATION TO THE IPSILATERAL CANINE TOOTH. CAT 12156 


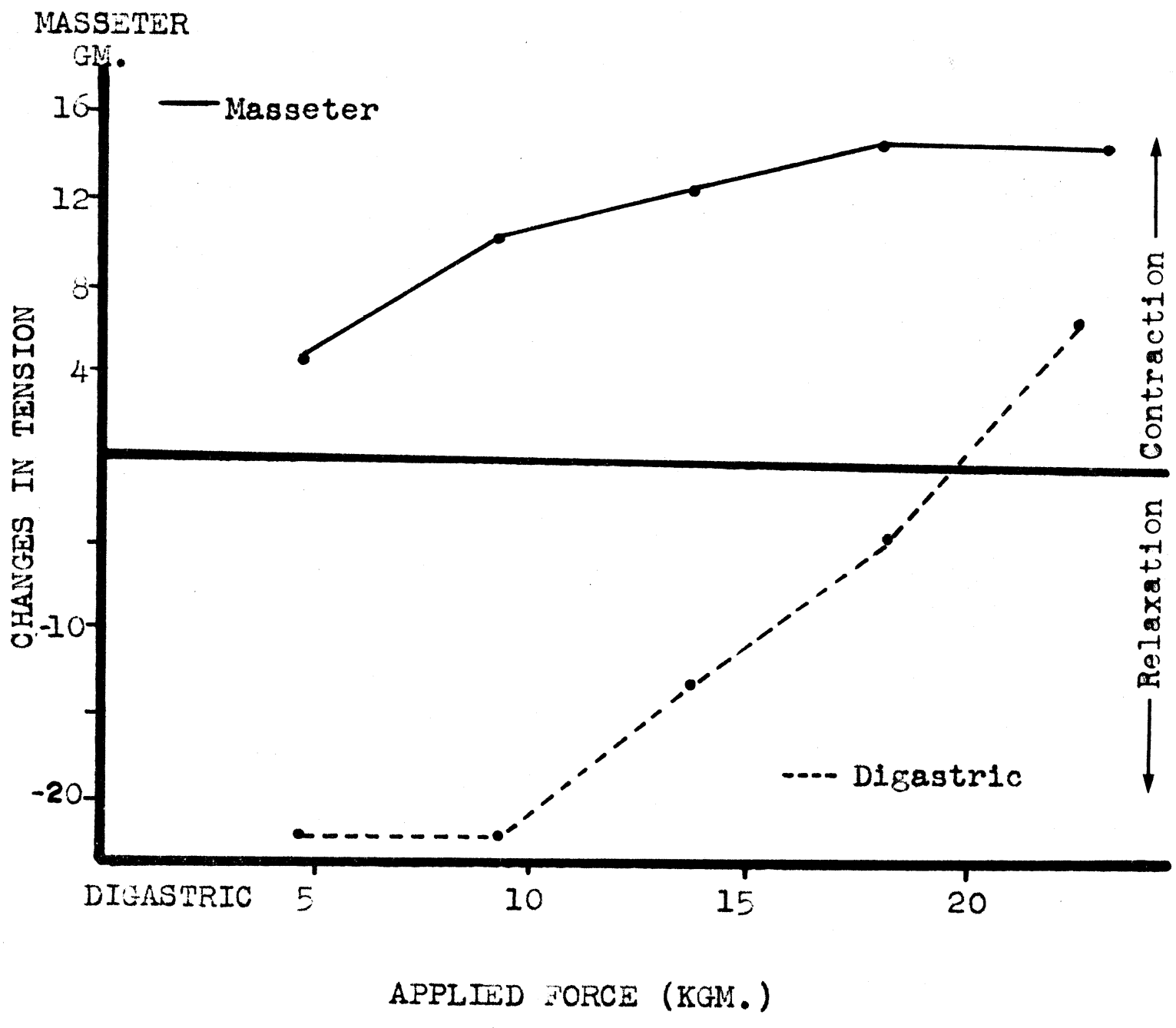

FIGURE 16

TINSION OF THE MASSETER AND DIGASTRIC MUSCIES PLOTTED AGAINS'I HIGH FORCE APPLICATION TO THE IPSILATERAL CANIIE TOOTH. ILLUSTRATES RECIPROCAL INNERVATION. CAT 12026. 


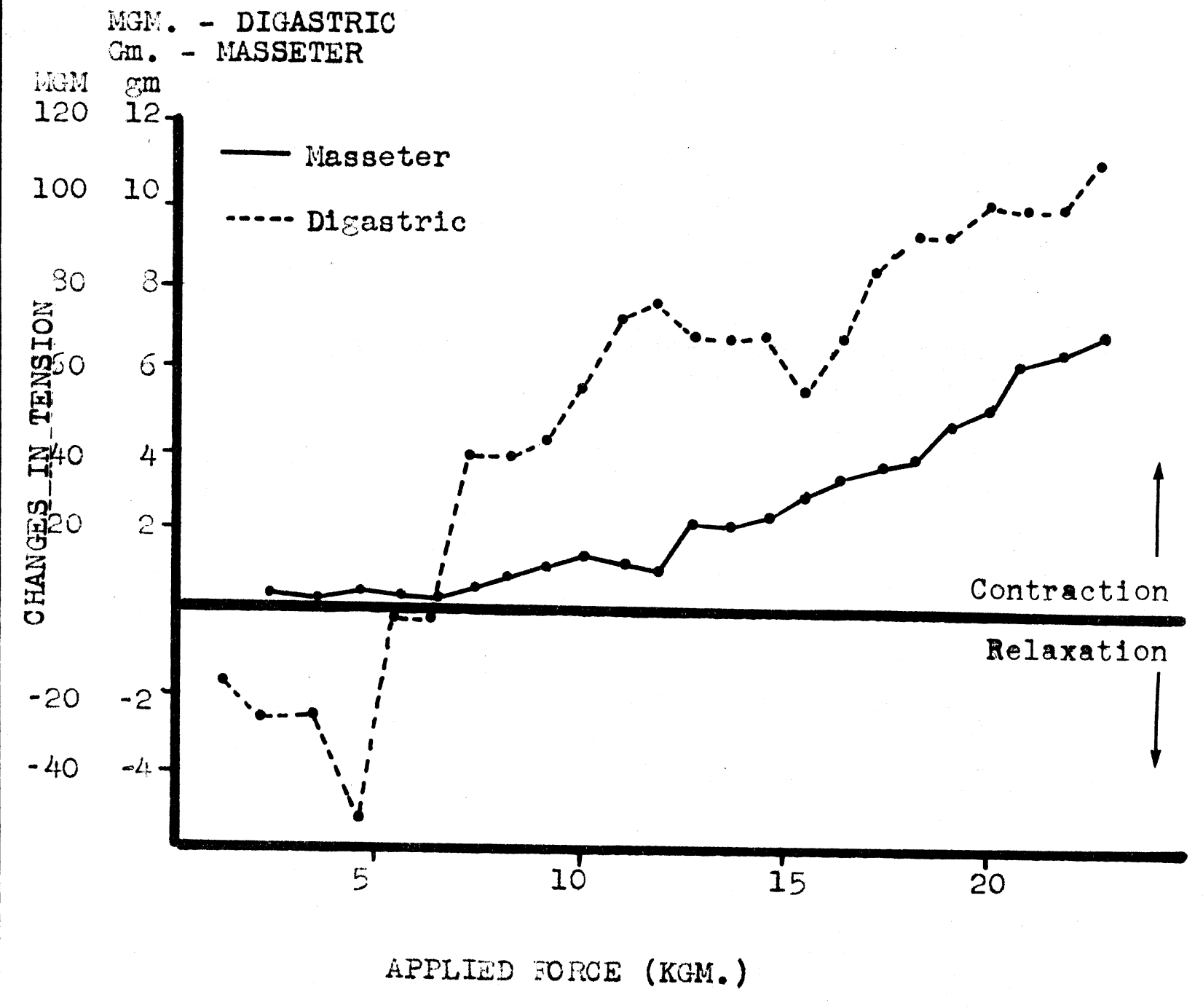

FIGURE 17

TENSION OF THE MASSETER AND DIGASTRIC MUSCLES PLOTTED

AGAINST HIGH FORCE APPLICATION TO THE IPSILATERAL CANINE TOOTH. CAT 01097 


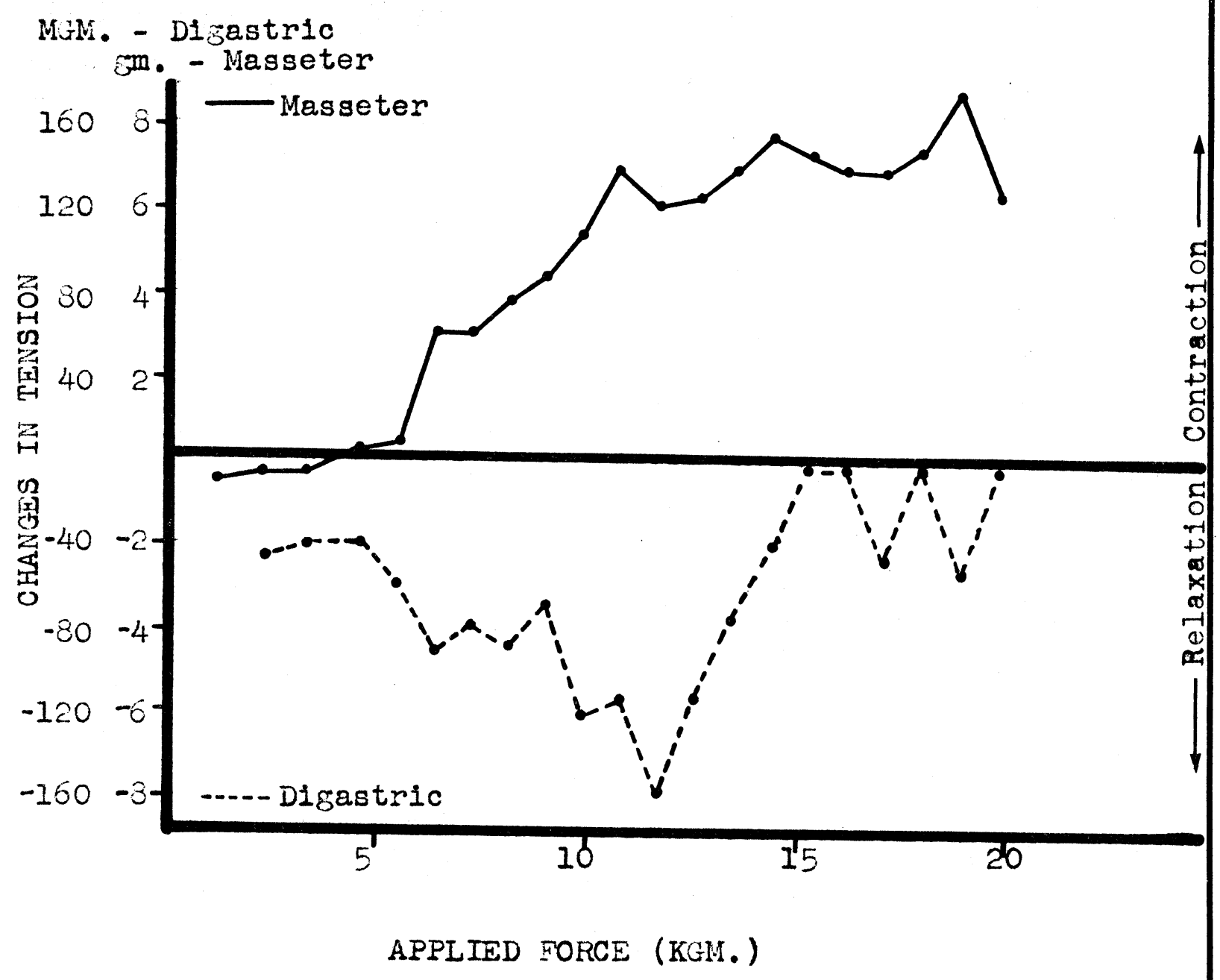

FIGURE 18

TENSION OF THE MASSETER AND DIGASTRIC MUSCLES PLOTTED AGAINST HIGH FORCE APPLICATION TO THE IPSILATERAL CANINE TOOTH. CAT 12156 


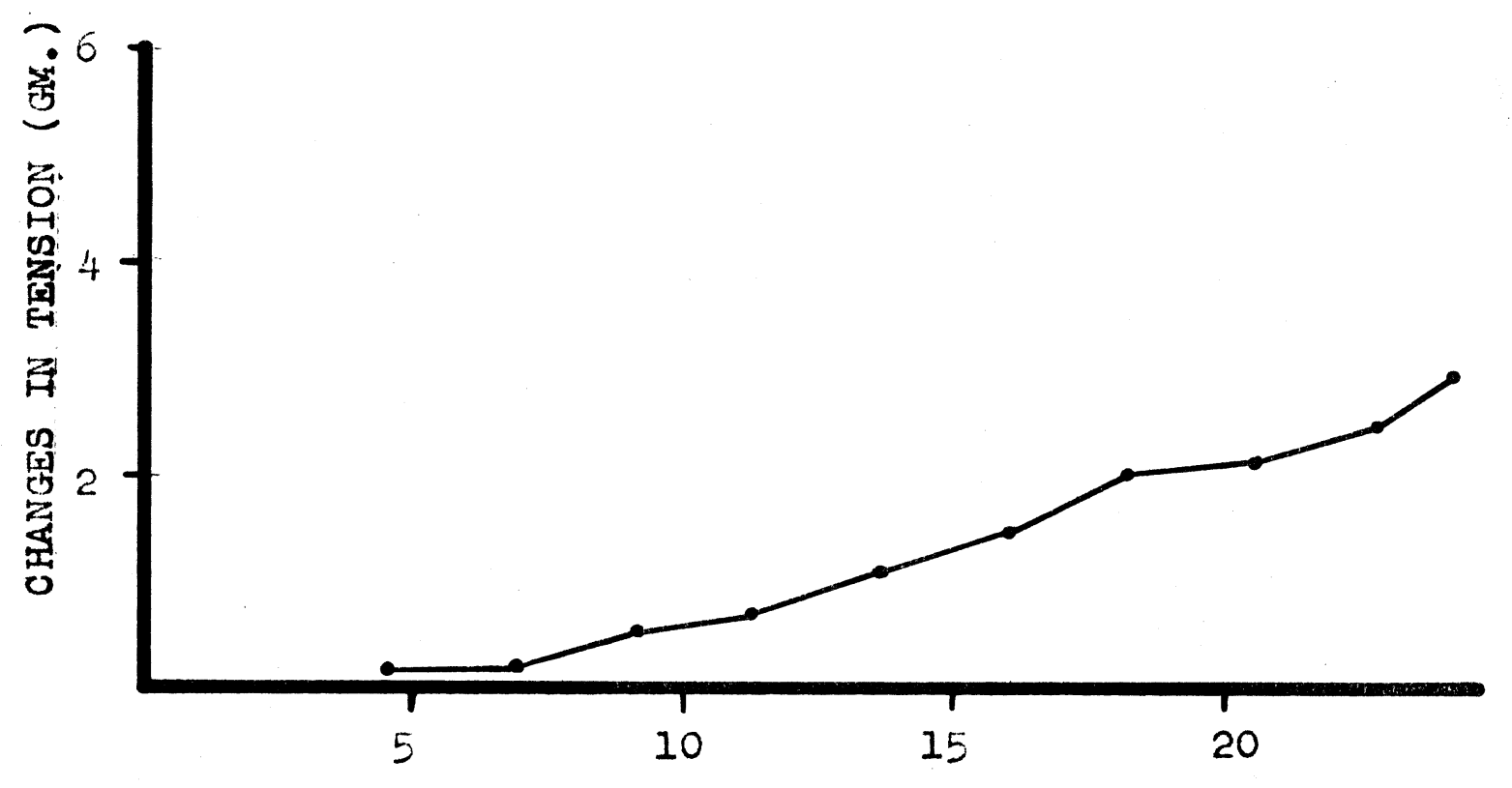

APPLIED FORCE (KGM.)

FIGURE 19

TEISION OF THE MASSETER MUSCLE PLOTTED AGAINST HIGH FORCE APPLICATION TO THE IPSILATERAL CANIINE TOOTH. CAT 11286 


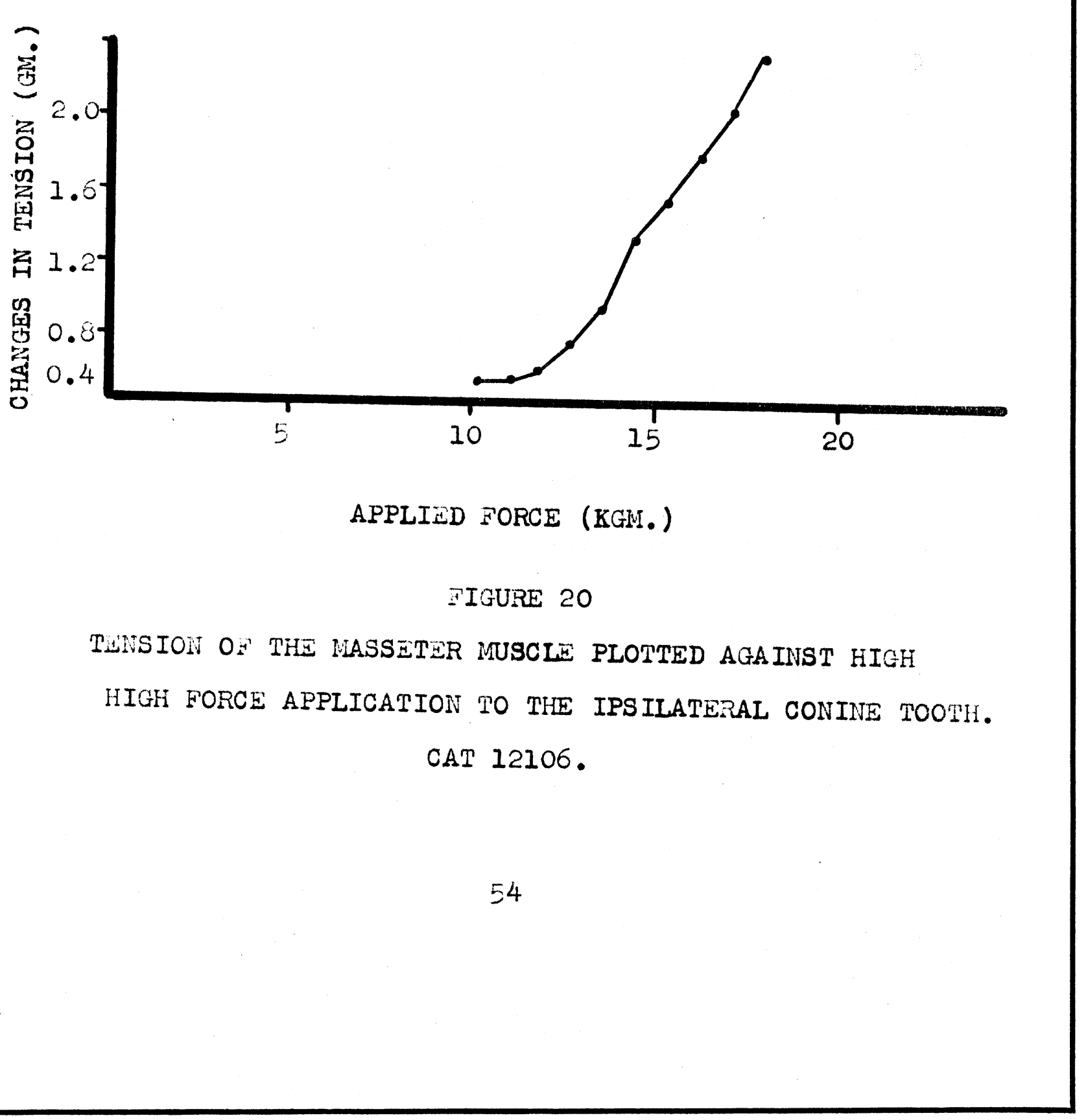




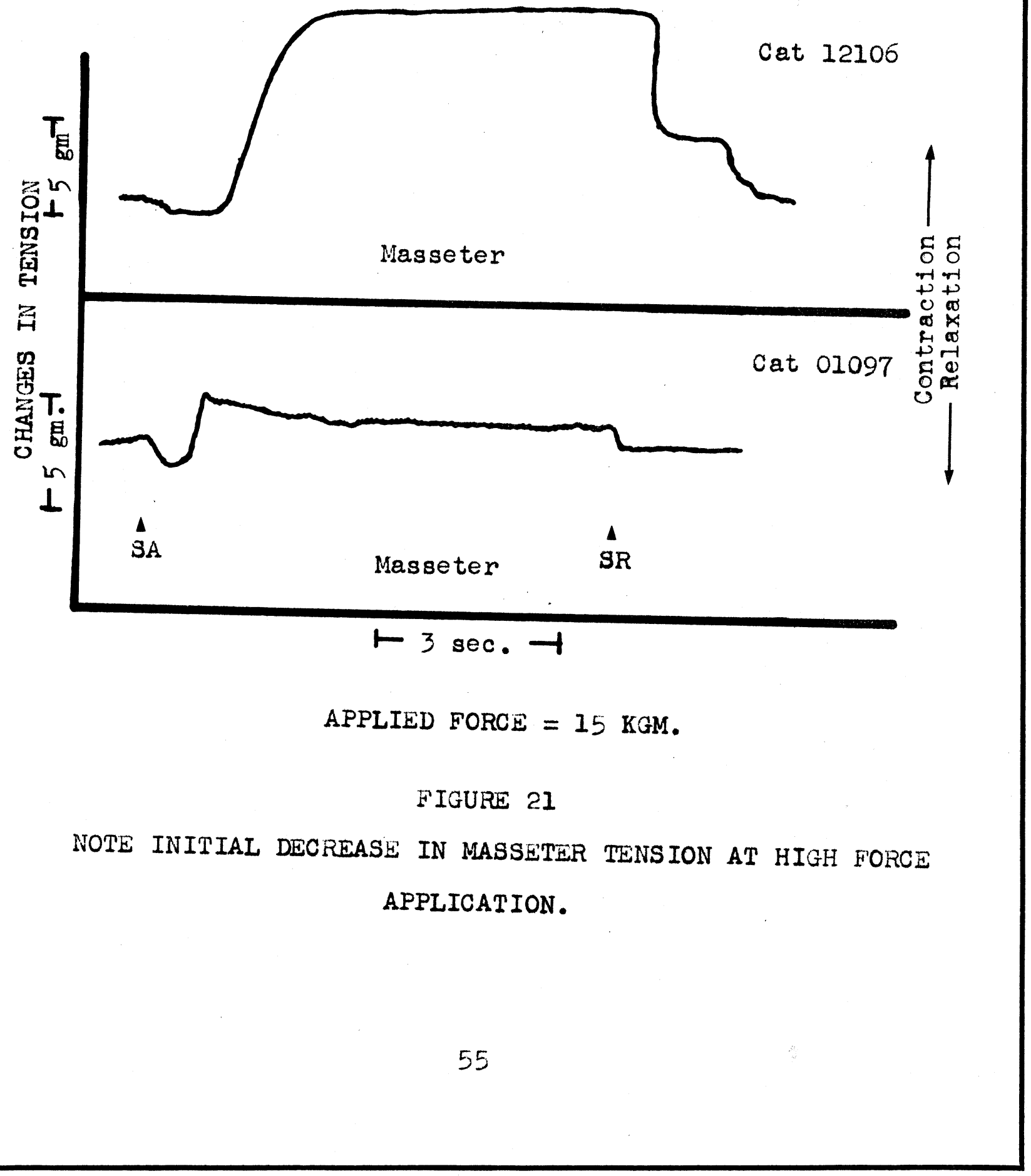




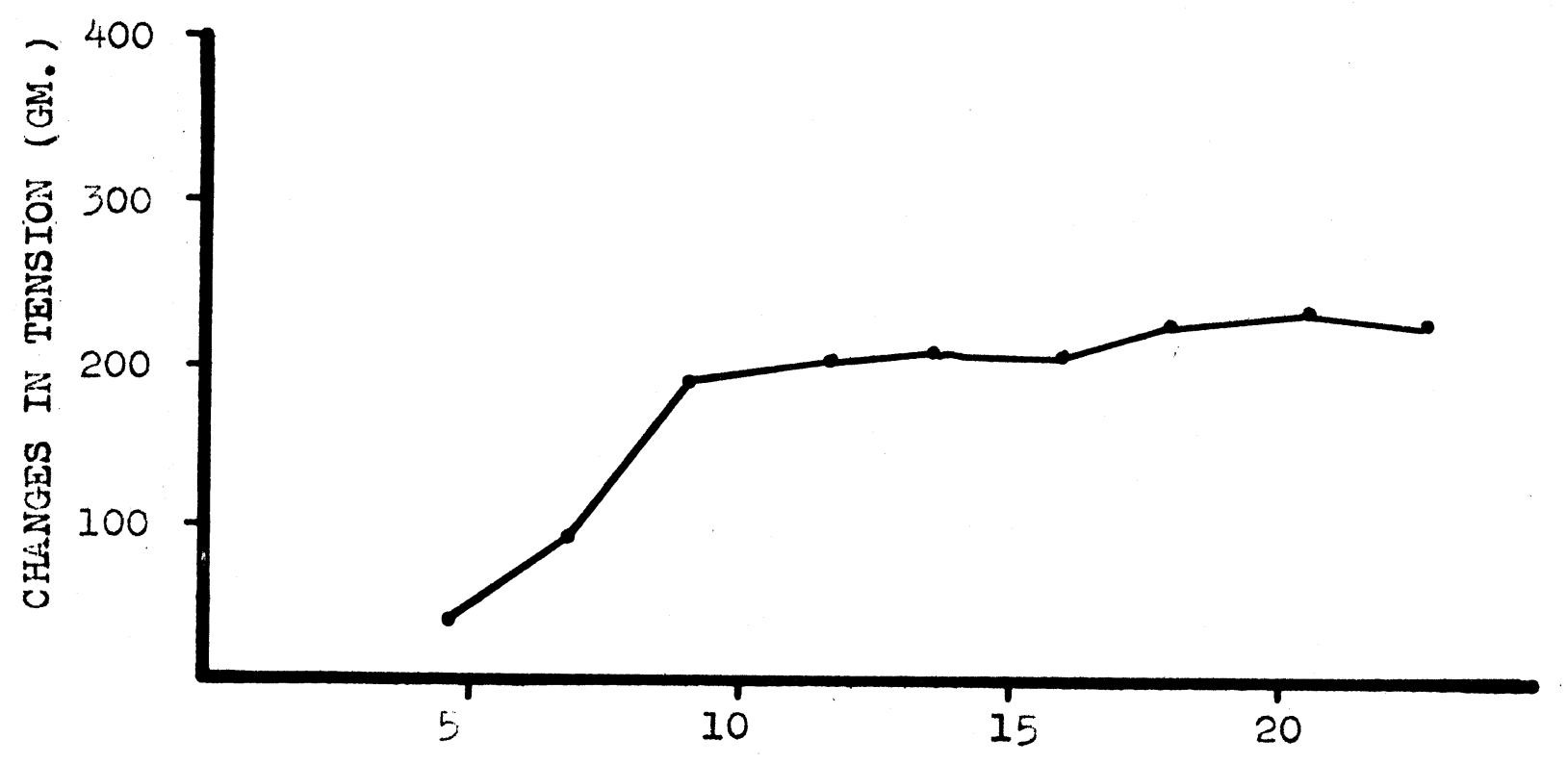

\section{APPLIED FORCE (KGM.)}

\section{FIGURE 22}

DIGASTRIC TENSION PLOTTID AGAINST HIGH FORCE APPLICATION TO THE IPSILATERAL CANINE TOOTH. CAT 11286 


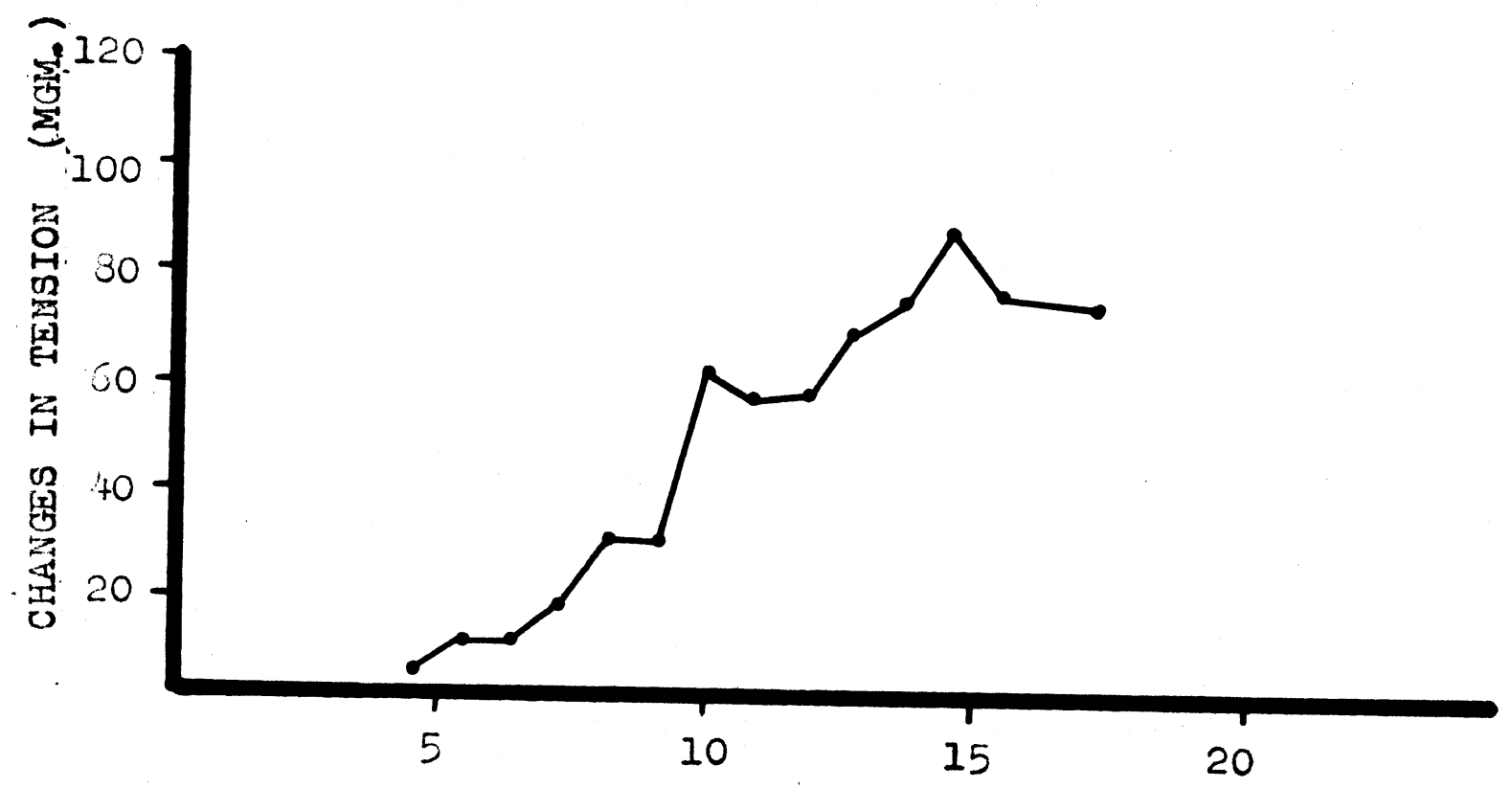

APPLIED FORCE (GM.)

FIGURE 23

DIGASTRIC TENSION PLOTTED AGAINST HIGH FORCE APPLICATION TO THE IPSILATERAL CANINE TOOTH. CAT 12106.

57 

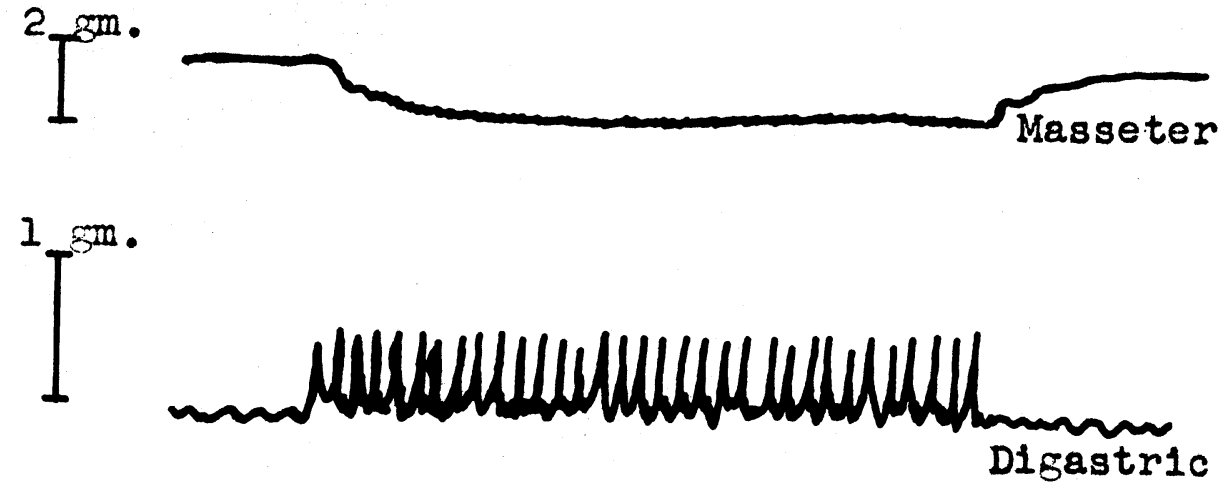

10 volts 5 pulses per/sec.

$2 \mathfrak{L}^{\mathrm{m}}$

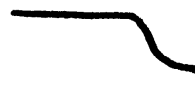

Masseter

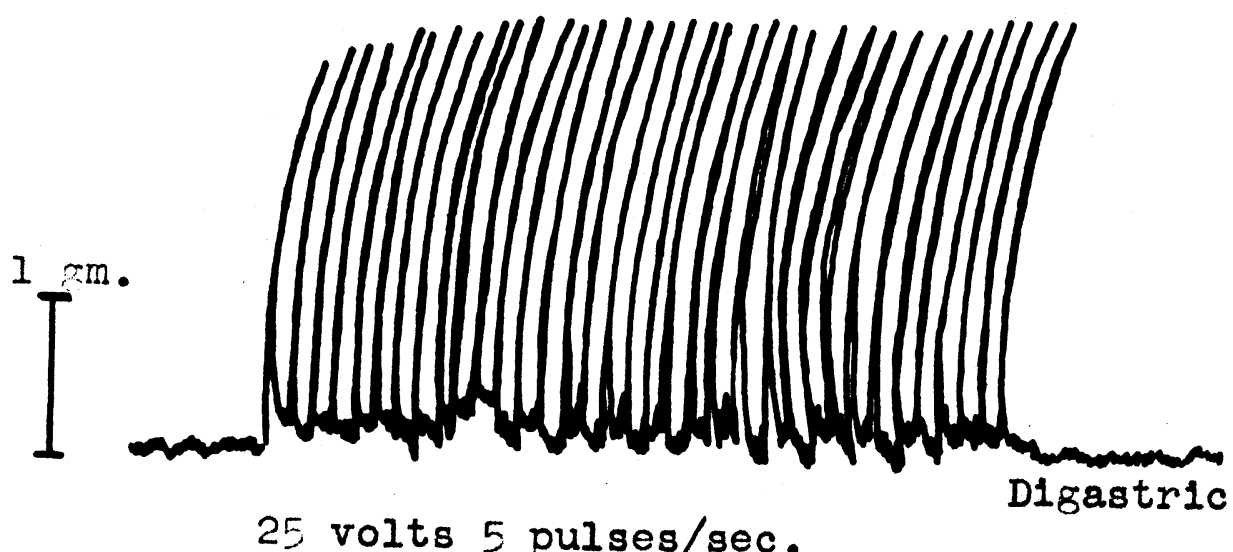

SA

SR

FIGURE 24

STIMULATION OF THE PALATAL GINGIVA AND COMPARISON OF THE MUSCLE RESPONSE TO STIMULUS INTENSITY. CAT 12106 


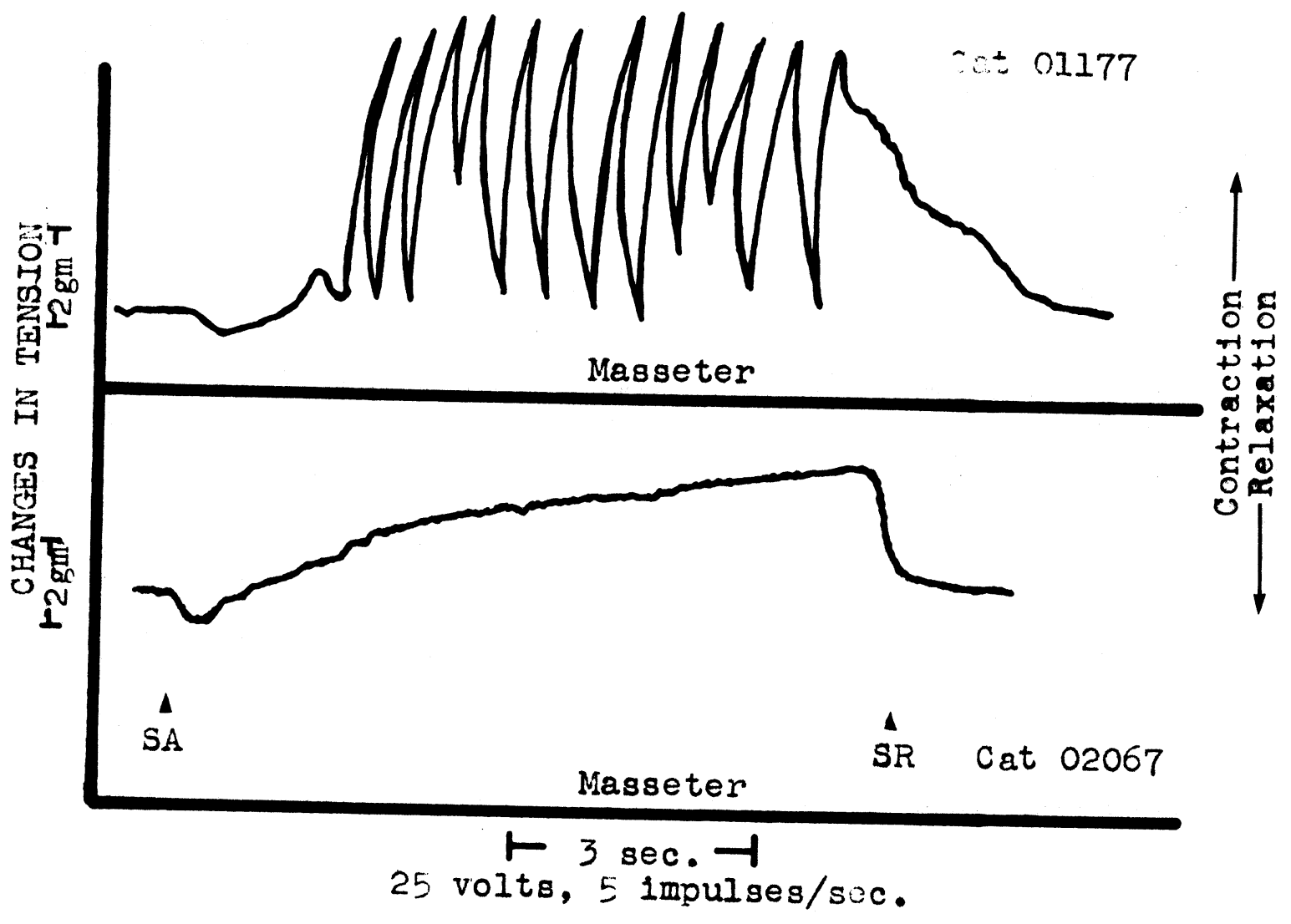

FIGURE 25

NOTE INITIAL DECREASE IN MASSETER TENSION UPON ELECTRICAL STIMULATION OF THE DENTAL PULP. 


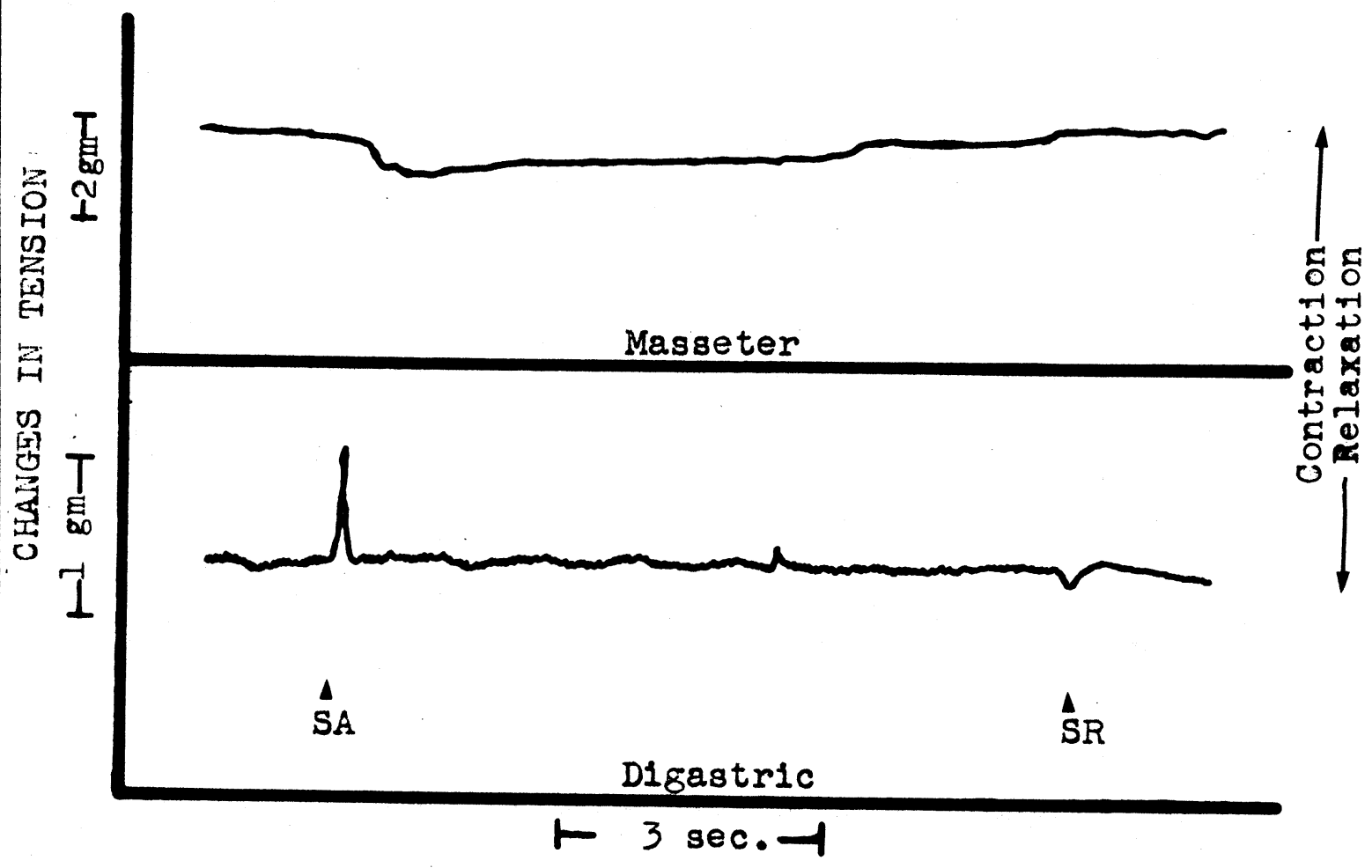

FIGURE 26

MECHANICAL STIMULATION WITHIN THE MAXILLARY CANINE PULP CHAMBER. CAT. 01177. 


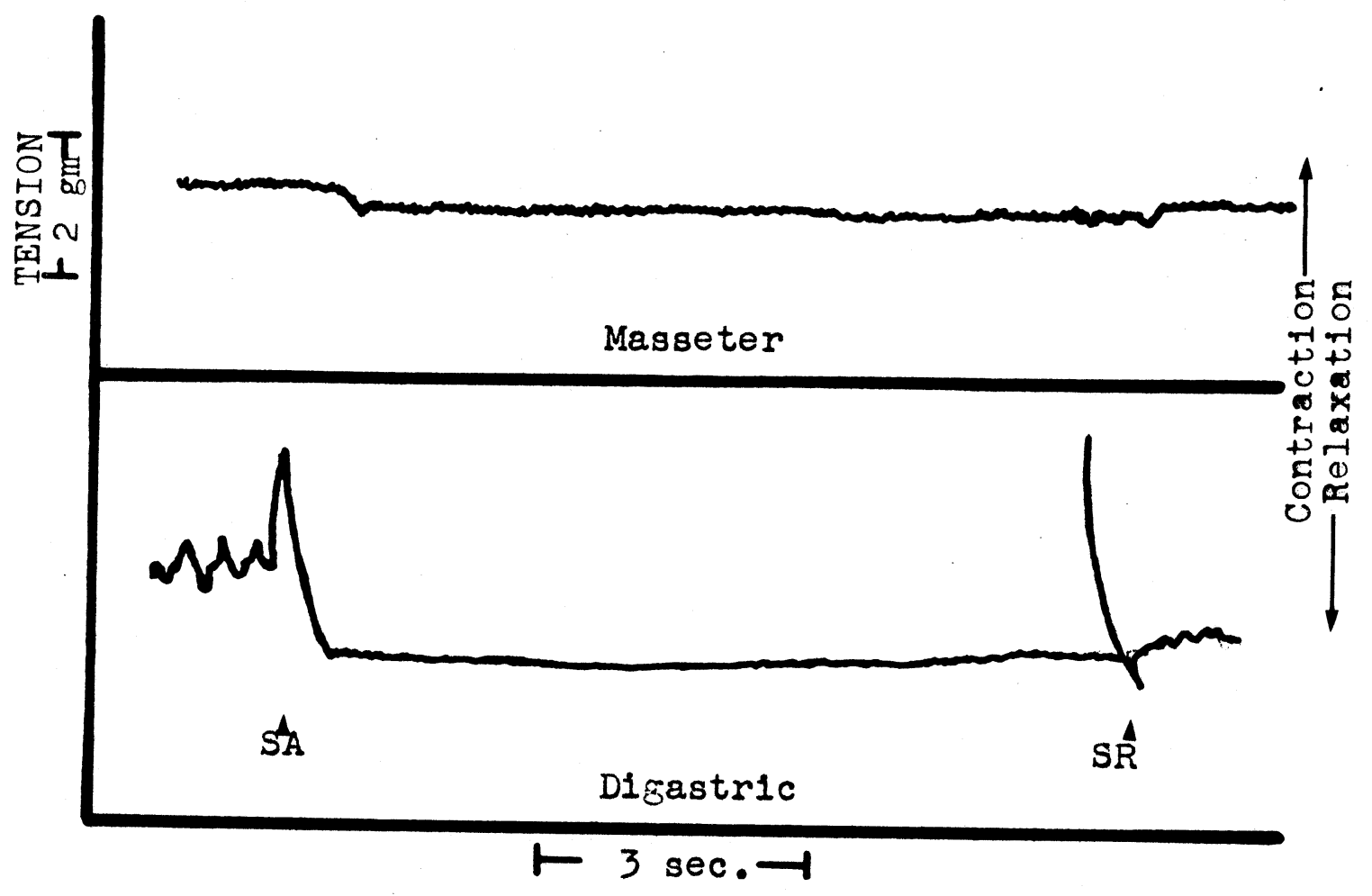

FIGURE 27

MAIUUAL STRETCH OF THE DIGASTRIC SHOWING MASSETER RELAXATION. CAT 02067 


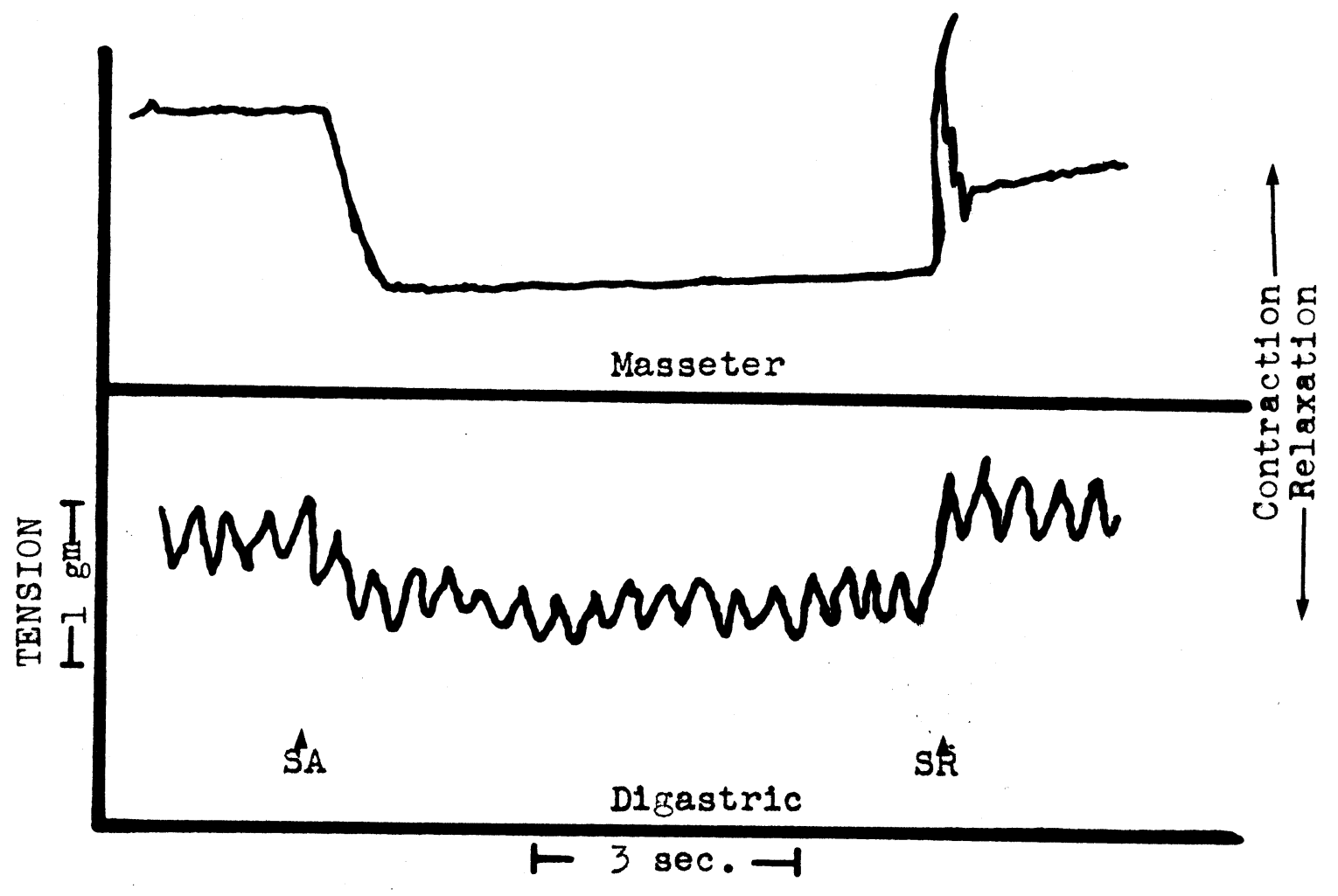

FIGURE 28

MANUAL STRETCH ON THE MASSETER SHOWING DIGASTRIC RELAXATION. CAT 121067 
THE CHANGES IN TENSION OF THE MASSETER MUSCLE FOR LOW FORCE APPIICATION TO THE IPSILATERAL CANINE TOOTH

$$
\begin{aligned}
+ & =\text { Contraction } \\
- & =\text { Relaxation } \\
\text { NR } & =\text { No response }
\end{aligned}
$$

$\begin{array}{cccccc}\begin{array}{l}\text { Grams of } \\ \text { Applied } \\ \text { Force }\end{array} & \begin{array}{c}\text { Cat } \\ 09306\end{array} & \begin{array}{c}\text { Grams of } \\ \text { Cat }\end{array} & \begin{array}{c}\text { Tension } \\ \text { Cat }\end{array} & \begin{array}{c}\text { Change } \\ \text { Cat }\end{array} & \begin{array}{c}\text { Cat } \\ 100\end{array} \\ \text { NR } & \text { NR } & \text { NR } & \text { NR } & \text { NR } \\ 200 & \mathrm{NR} & \mathrm{NR} & \mathrm{NR} & \mathrm{NR} & \mathrm{NR} \\ 300 & \mathrm{NR} & \mathrm{NR} & \mathrm{NR} & +0.25 & \mathrm{NR} \\ 400 & \mathrm{NR} & \mathrm{NR} & \mathrm{NR} & +0.27 & \mathrm{NR} \\ 500 & +0.15 & +0.48 & \mathrm{NR} & +0.31 & \mathrm{NR} \\ 600 & +0.19 & +0.69 & +0.08 & +0.27 & \mathrm{NR} \\ 700 & +0.19 & +0.93 & +0.10 & +0.27 & \mathrm{NR} \\ 800 & +0.27 & +1.16 & +0.27 & +0.29 & \mathrm{NR} \\ 900 & +0.28 & +1.40 & +0.27 & +0.31 & \mathrm{NR} \\ 1000 & +0.34 & +1.44 & +0.40 & +0.31 & +0.07 \\ 1100 & +0.40 & +1.96 & +0.43 & +0.29 & +0.10 \\ 1200 & +0.52 & +2.04 & +0.57 & +0.34 & +0.14 \\ 1300 & +0.52 & +2.17 & +0.70 & +0.34 & +0.16 \\ 1400 & +0.56 & +2.47 & +0.73 & +0.45 & +0.25 \\ 1500 & +0.59 & +2.65 & +0.76 & +0.50 & +0.25\end{array}$


THE CHANGES IN TENSION OF THE DIGASTRIC MUSCLE FOR LOW FORCE APPLICATION TO THE IPSILATERAL CANINE TOOTH

$+=$ Contraction

- = Relaxation

$\mathrm{NR}=$ No response

Grams of Applied Force

100

200

300

400

500

600

700

800

900

1000

1100

1200

1300

1400

1500
Grams of Tension Change

$\begin{array}{cccccc}\text { Cat } & \text { Cat } & \text { Cat } & \text { Cat } & \text { Cat } & \text { Cat } \\ 09306 & 11116 & 11146 & 11286 & 12026 & 12156\end{array}$

NR

NR

NR

NR

NR

NR

NR

NR

NR

$-0.018$

NR

NR

NR

NR

NR

$-0.025$

NR $-0.026$

NR

NR

$-0.053$

$-0.031$

NR

$-0.085-0.031$

NR

$-0.021$

NR

$-0.118 \quad-0.018$

NR

NR

NR

$-0.031$

$\begin{array}{llll}-0.056 & -0.500 & -0.182 & -0.031\end{array}$

$-0.002$

$-0.025$

$-0.002$

$-0.056-0.062$

$-0.182$

$-0.025$

$-0.160$

$-0.056$

$-0.003$

$-0.072$

$-0.08$

$-0.070$

$-0.160$

$-0.056$

$-0.00$

$-0.052$

$-0.07$

$-0.070$

$-0.160$

$-0.056$

$-0.07$

$-0.052$

$-0.088$

$-0.070$

$-0.214$

$-0.069$

$-0.01$

$-0.039$

$-0.088 \quad-0.070$

$-0.182$

$-0.085$

$-0.010 \quad-0.033$ 
THE CHANGES IN TENSION OF THE MASSETER MUSCLE FOR HIGH FORCE APPLICATION TO THE IPSILATERAL CANINE TOOTH

$\begin{aligned}+ & =\text { Contraction } \\ - & =\text { Relaxation } \\ N R & =\text { No response }\end{aligned}$

Applied Force in Kilograms

1.1

2.2

3.4

4.5

5.5

7.3

8.2

9.1

10.0

10.9

11.8

12.7

13.6

14.5

15.4

16.3

17.2

18.0

18.9

19.8

20.7

21.6

22.5

25.0
Grams of Tension Change

Cat Cat cat Cat

$\begin{array}{llll}11286 & 12026 & 12106 & 12156\end{array}$

$\begin{array}{ccccc}N R & N R & N R & -0.43 & N R \\ N R & N R & N R & -0.15 & +0.22 \\ N R & N R & N R & -0.15 & +0.14 \\ +0.05 & +4.57 & N R & +0.19 & +0.39 \\ & & N R & +0.39 & +0.39 \\ +0.27 & & N R & +3.24 & +0.28 \\ & & N R & +3.24 & +0.64 \\ +0.66 & +10.25 & \text { NR } & +3.90 & +0.92 \\ & & +0.14 & +4.49 & +1.12 \\ +0.77 & & +0.14 & +5.47 & +1.40 \\ & & +0.22 & +7.15 & +1.29 \\ +1.22 & +12.70 & +0.36 & +6.25 & +1.51 \\ & & +0.56 & +6.36 & +2.26 \\ +1.55 & & +0.95 & +7.03 & +2.05 \\ & & +1.15 & +7.81 & +2.38 \\ & & +1.41 & +7.42 & +2.86 \\ +2.11 & +14.95 & +1.55 & +7.03 & +3.38 \\ & & +1.94 & +7.03 & +3.70 \\ & & & +7.45 & +3.98 \\ +2.27 & & & +9.20 & +4.77 \\ & & & +6.48 & +5.10 \\ +3.08 & +16.75 & & & +6.17 \\ +3.33 & & & & +6.50 \\ & & & & \end{array}$


THE CHANGES IN TENSION OF THE DIGASTRIC MUSCLE FOR HIGH FORCE APPLICATION TO THE IPSILATERAL CANINE TOOTH

$+=$ Contraction

- = Relaxation

$\mathrm{NR}=$ No Response

$\begin{array}{lccccc}\begin{array}{c}\text { Applied } \\ \text { Force in }\end{array} & \text { Cat } & \begin{array}{c}\text { Grams of } \\ \text { Cat }\end{array} & \begin{array}{c}\text { Tension } \\ \text { Cat }\end{array} & \begin{array}{c}\text { Change } \\ \text { Cat }\end{array} & \text { Cat } \\ \text { Kilograms } & 11286 & 12026 & 12106 & 12156 & 01097 \\ & & & & -0.099 & -0.017 \\ 1.1 & & & & -0.040 & -0.025 \\ 2.2 & & & -0.039 & -0.025 \\ 3.4 & & & & -0.039 & -0.051 \\ 4.5 & +0.037 & -0.023 & +0.006 & -0.059 & \text { NR } \\ 5.4 & & & +0.012 & -0.059 \\ 6.3 & +0.094 & & +0.012 & -0.092 & \text { NR } \\ 7.2 & & & +0.019 & -0.079 & +0.038 \\ 8.1 & & & +0.031 & -0.086 & +0.038 \\ 9.0 & +0.189 & -0.023 & +0.031 & -0.066 & +0.042 \\ 9.9 & & & +0.063 & -0.119 & +0.055 \\ 10.8 & & & +0.050 & -0.112 & +0.072 \\ 11.7 & +0.202 & & +0.050 & -0.158 & +0.076 \\ 12.6 & & & +0.070 & -0.112 & +0.068 \\ 13.5 & +0.208 & -0.014 & +0.076 & -0.0726 & +0.068 \\ 14.4 & & & +0.089 & -0.0396 & +0.068 \\ 15.3 & & & +0.076 & \text { NR } & +0.055 \\ 16.2 & +0.208 & & +0.102 & \text { NR } & +0.068 \\ 17.1 & & & +0.070 & -0.0463 & +0.085 \\ 18.0 & +0.221 & -0.004 & +0.044 & \text { NR } & +0.093 \\ 18.9 & & & & -0.052 & +0.093 \\ 19.8 & & & & \text { NR } & +0.102 \\ 20.7 & +0.227 & & & & +0.102 \\ 21.6 & & & & +0.102 \\ 22.5 & +0.252 & +0.007 & & & +0.102 \\ 23.4 & +0.328 & & & & \end{array}$


TENSIONS DEVELOPED BY THE MASSETER AND DIGASTRIC WHEN VARIED ELECTRICAL POTENTIALS OF CONSTANT FREQUENCY ARE APPLIED TO THE PALATAL GINGIVA. CAT 12106

$$
\begin{aligned}
+ & =\text { Contraction } \\
- & =\text { Relaxation } \\
\text { NR } & =\text { No Response }
\end{aligned}
$$

Applied Voltage

5

10

25

50
Masseter Tension (grams)

$-1.42$

$-2.07$

$-2.44$

$-2.44$
Digastric Tension (grams)

NR

$+1.0$

$+45.5$

$+44.3$

TABLE 5 


\section{CHAPTER V}

\section{DISCUSSION}

Force applications in the ranges of $100 \mathrm{gm}$. to $1500 \mathrm{gm}$. applied to the teeth evoked an increase in masseter tension and a reduction of the ipsilateral digastric tension. These results corroborate the findings of Harrison and Corbin (1942). The mean proprioceptive threshold recorded for the masseter was $580 \mathrm{gm}$., while that for the digastric was $517 \mathrm{gm}$. These threshold values indicated that the tension changes within the digastric occurred before those in the masseter. Mandibular elevation is associated with potentials in the trigeminal mesencephalic nucleus which results in contraction of the masseter and inhibition of the digastric (Harrison and Corbin, 1940 and Kawamura et al. 1959). This evidence suggests that the threshold.values should be more nearly equal or that the masseter should show tension changes before the digastric.

The explanation for this difference in apparent threshold values may be associated with the length tension 
relationship of the muscles. Ruch and Patton (1965) state that a muscle exerts its greatest contractile forces when the initial lengths of the muscle fibers approximate the resting lengths of the muscle in vivo. In this investigation one end of each the masseter and the digastric was detached from the animal and connected to myographs. A traction force of only $30 \mathrm{gm}$. was needed to cause. maximum deflection of the masseter myograph. Therefore, if any-sensitivity was to remain in this transducer, the initial stretch force imparted to the attached muscle must be below $30 \mathrm{gm}$. The much thinner, somewhat fusiform digastric could be stretched more than the masseter when these muscles were attached to the myographs. Consequently, the determination of the threshold value for the reflex contraction of the digastric mascle was more sensitive than that of the masseter.

The threshold sensitivity of the digastric becomes more significant when inputs of the ipsilateral internal pterygoid and the temporalis muscles are considered. The animal!s mandible was fixed in wide open position placing definite traction upon these muscles. Kawamura 
(1964) demonstrated summation of responses in the trigeminal motor nucleus, when synergistic muscles are stretched. The masseter received additional stimuli to contract because of the reflex facilitatory potentials arising from the stretched ipsilateral temporalis... It must be reasoned that the masseter received adequate contractile. stimuli but yet failed to precede the digastric change. This failure, as previously mentioned, may best be attributed to the inadequate initial stretch placed upon the masseter.

The threshold force reguired to evoke a response to tooth stimulation has been widely reported in the literature: Stewart (1927) 17-21 gmo; Pfaffmann (1939) 2-3 gm.; Loewenstein and Rathkamp (1954) 2.52 gm.; Jerge (1963) $1.8 \mathrm{gm}$; and Cuozzo (1966) 4 gm. These values present a striking contrast to the $580 \mathrm{gm}$. and 517 gm. thresholds exhibited by the masseter and the digastric respectively in this study... With the exception of Stewart, these investigators obtained their threshold values from bioelectric potentials_of the inferior alveolar nerve or within the trigeminal main sensory 
nucleus and trigeminal spinal root. Any stimulus of sufficient magnitude to excite the receptors in the periodontal ligament would be transmitted directly to the recording apparatus without crossing any interposed synapses. This investigation, however, involved the entire spectrum of nerve pathways beginning with the inception caused by tooth stimulation and its completion demonstrated by changes in muscle tension. The bioelectric potential in this complex nerve pathway traverses many synapses and is subject to a host of modifying factors which manifest themselves in higher threshold values for reflex activity.

The trigeminal motor nucleus is the proximal end of the final common pathway to the muscles of mastication and receives fibers from the cortex, the ipsilateral and contralateral mesencephalic nucleus as shown by Kawamura (1964). Depression of the cerebral cortex as it occurs in general anesthesia has a definite relationship to the force threshold in this experiment. Blier and Kleitman (1930) reported that the jaw reflex was markedly altered by ether anesthesia. Blais, Langier, and Robillard 
(1943) found that the depth of anesthesia could be determired from the response of the linguo-maxillary reflex as a result of electrical stimulation applied to the tip of the tongue. The electrical potential required to evoke a response increased as the level of anesthesia became more profound. The level of anesthesia was adjusted in this investigation to reduce pain and nervous irritability while maintaining maximum reflex responses.

The myotatic reflex due to stretch of either the ipsilateral masseter or digastric was eliminated by the stereotaxic device. This device stabilized the head in such a way as to prevent the contraction in one muscle from effecting its antagonist through their fascial attachments to mutually continguous structures. The head fixed in this position checked the movements that could initiate stretch of the masseter and digastric muscles since each muscle was attached at one end to the myograph. Tension changes of the ipsilateral masseter and digastric muscles would not wholly reflect responses due to tooth stimulation if the myotatic reflex was operative in them. 
The upper jaw was rigidly held to the stereotaxic device by the palatal bar. The palatal bar was situated transversely across the maxillae engaging the distal cusps of the maxillary fist molar teeth. The compressive force which stabilized the maxillae necessarily stimulated the receptors in the periodontal ligaments of these teeth. Eisenman et. al. (1963) demonstrated that receptive fields of the periodontal cells occurred within the main trigeminal sensory nucleus and the trigeminal spinal tract. They stated that within these receptive fields there was frequent convergence from several teeth and sometimes from ipsilateral incisors and molars. In the same year Jerge (1963) reported electrical activity arising from two types of dental pressoreceptors within the mesencephalic trigeminal nucleus. These pressoreceptors had their origin in the periodontal ligament of the tooth. The Type I dental pressoreceptor responded only to pressure applied to individual teeth and the maxillary first molar was represented in this group of teeth. The Type II pressoreceptor innervated groups of teeth. The data presented by Eisenman and Jerge demonstrates 
the feasibility of spatial summation of stimuli resulting from forces upon the molar and canine teeth. Stimuli from two sources imply that the actual threshold force is higher than that recorded.

A final factor which may contribute to the high threshold force associated with these reflexes is the number of receptor cells in the periodontal ligament of the maxillary canine. The tooth functions in the prehension of food and in combat. These uses are necessarily traumatic and were the periodontal ligament highly innervated the animal would experience pain more frequently. Bernick (1957) concurs with the opinion that the periodontal ligament is not richly endowed with nerve receptors. Consequently, these conducted..impulses received in the trigeminal mesencephalic nucleus and trigeminal main sensory nucleus may have been of insufficient magnitude to effect an easily measured response. Greater force upon the tooth would then be required to recruit enough fibers to produce a measurable change in muscle tension. A force exerted upon the incisal edge of a tooth parallel to its long axis produced optimal responses. 
This fact had been adequately substantiated by Pfaffmann (1939), Ness (1954), Kruger and Michel (1962), Jerge (1963), and Cuozzo (1966). Incisal stimulation was also employed in this study to obtain maximal muscle response. The canine tooth was selected because of its reported sensitivity by Harrison and Corbin (1940), Jerge (1963), and Cuozzo (1966). The accessibility of the canine tooth was a secondary consideration in its selection.

The masseter continued its progressive increase in tension as the force applied to the tooth ranged from $1.5 \mathrm{kgm}$. to $23 \mathrm{kgm}$. The graph of Figures 7-11 illustrate this general increase in tensions. Increased force upon the tooth emulates a condition during mastication in which the masseter forcibly contracts as the mandible approaches centric occlusion. That the masseter is the power muscle during mastication and not primarily a postural muscle of the mandible has been reported by Moyers (1950), Carlsoo (1952), Jarabak (1954), and Perry and Harris (1954)... These graphs do not reveal a significant activity of the muscle as shown on the physiograph recording. Application of high forces 
evoked a characteristic response in the masseter which appeared with moderate consistency (Figure 18). The masseter demonstrated an initial transient decrease in tension followed immediately by contraction. These transient reductions in masseter tension never appeared below $8 \mathrm{kgm}$. of force application, but thereafter were present sporadically to the maximal levels of tooth stimulation used in this study. The force increment changes during the contractile phase far surpassed those that occurred during this initial stage... The longevity of the contractile phase exceeded that of the initial stage by at least a factor of ten. It should be further noted that some records displayed a short lapse of time from the onset of tooth stimulation to the initiation of masseter contraction.

Identical responses have been obtained from the masseter when the pulp of the canine tooth was stimulated with an electric potential (Figure 19). In this figure, Cat 01177 displays this initial transient decrease in tension with a subsequent rythmic contraction in phase with the pulsating electric current used to stimulate 
the pulp. Pulpal stimulation of teeth is a widely accepted method of inducing pain stimuli. Therefore, the initial transient stage in masseter changes of tension is the first manifestation of its reaction to pain. Subsequent contraction of the masseter constitutes the second stage of this response to pain.

High force magnitudes evoked the following responses in the digastric muscle. The muscle displayed increased changes of tension. throughout the range of force application (Figure 10, 11) or it displayed alternating decreases of changes of tension throughout this range (Figure 9). The third mode of action combined elements of both previous patterns. (Figure 7, 8). Decreased changes of tension were observed at the lower range of force application. Subsequent increased tension changes occurred as the force magnitudes increased. The earlier portion of this mode of action is a continuation of the reciprocal action of the masseter and digastric muscles evident at the low force magnitudes. The force exerted upon the mandible during these high force applications to the canine tooth evoked stronger contractions 
of the masseter. Stronger contractions of the digastric are required to control and stabilize mandibular movements. The role of the digastric muscle in stabilization of the mandible has been well documented by Moyers (1950), Carlsoo (1956), Perry and Harris (1954) and Hickey (1957)。

Kawamura et al. (1959) observed the hypoglossal nucleus to be reciprocally inhibited when the mesencephalic nucleus is active. Morphologic evidence presented by Szentagothai (1948) demonstrated reflex collaterals from the trigeminal mesencephalic nucleus to the hypoglossal nucleus. The hypoglossal nucleus is the cell body site of the motor nerves which innervate the infrahyoid musculature. The role of the digastric then is two-fold: to stabilize the mandible and to elevate the hyoid bone. It seems contradictory that the digastric can fulfill both functions, but the key to understanding its role is that the infrahyoid muscles are not completely inhibited. This prevents total movement of the hyoid in a superior direction and affords anchorage to the digastric.

Sherrington (1917), Cardot and Laugier (1923), Blier and Kleitman (1930), Harrison and Corbin (1942), 
and Kawamura et al. (1959) have reported jaw opening in response to noxious stinuli to oral structures. The. digastrics are the principal muscles engaged during this movement. Contraction of the digastric occurs during the reaction to pain stimuli and to the usual response to tooth stimulation at these high force magnitudes. Consequently a marked registration of pain associated with alteration of the contraction pattern is not monitored in the digastric.

The reactions of the masseter and digastric muscles to pain exhibits marked differences and similarities. The initial response demonstrates masseter relaxation and digastric contraction causing the mandible to open. This response is associated with the transient stage in masseter contraction and is of short duration compared to the contraction stage. The contraction stage is marked by contraction of masseter and digastric muscles. This stage fixes the mandible in space.

Stretch of the ipsilateral masseter caused a decrease in digastric tension. Stretch of the ipsilateral 
digastric resulted in decreased masseter tension. These responses demonstrate reciprocal innervation first described by sherrington (1917). 


\section{CHAPTER VI}

\section{SUMMARY AND CONCLUSIONS}

Forces in this investigation ranged from $100 \mathrm{gm}$. to $23 \mathrm{kgm}$. The forces from $100 \mathrm{gm}$. to $1500 \mathrm{gm}$. are referred to as low force magnitudes, while those from $1.5 \mathrm{kgm}$. to $23 \mathrm{kgm}$. are termed high force magnitudes. The masseter muscle demonstrated increases in tension throughout the low force range while the digastric muscle displayed decreased tension during the same range. The reciprocal action of these muscles was clearly established.

The mean reflex threshold for the masseter was $580 \mathrm{gm}$. while that for the digastric was $517 \mathrm{gm}$. The relatively high reflex threshold values have been attributed to the following factors: insufficient stretch upon the muscles and the consequent violation of their length-tension relationships; synaptic attenuation of the bioelectric potentials in their course from the periodontal ligament to the muscle; cortical depression resulting from ether narcosis; and the paucity 
of periodontal receptors.

The masseter displayed progressive and continued increases in tension at high force magnitudes. A characteristic change in its contraction pattern occurred when forces in excess of $8 \mathrm{kgm}$. were applied to the tooth. A transient decrease of masseter tension was noted immediately following the onset of force application. The muscle quickly returned to an increased contractile state whose duration exceeded that of the initial stage by a factor of ten. A transient decrease in tension was interpreted as a manifestation of pain since similar pain contraction patterns were obtained from records of electrical stimulation of the canine pulp chamber. Some records reported a short lapse of time from the beginning of tooth stimulation to the initiation of masseter contraction. It was believed that this phenomenon was an alteration of the transient decrease of the masseter tension pattern noted earlier.

The digastric muscle exhibited three contraction modalities at high force magnitudes; it demonstrated increased tensions throughout the range of force application, 
83

varying reductions in muscle tension, and an initial reduction in muscle tension followed by increased muscle tension. It was concluded that the digastric muscle functions in the dual capacity of stabilization of the mandible and elevation of the hyoid bone. 


\section{BIBLIOGRAPHY}

Bernick, S. Innervation of Teeth and Periodontium After Enzymatic Removal of Collagenous Elements. Oral Surg., Oral Med., and Oral Path., 1957, 10: $\overline{323-332 .}$

Blais, J.A., Laugier, H., and Robillard, E. Measure of the Depth of Anesthesia by Study of the LinguoMaxillary Reflex. Anesth. \& Analg., 1943, 22 : 15-27.

Blier, Z.A. and Kleitman, No Conditions Affecting the Linguo-Maxillary Reflex. Amer. J. Physiol., 1930 $94: 118-124$.

Cardot H. and Laugier, H. Le Reflexe Linguo-Maxillaire. C.R. Soc. Biol., 1922, 86:529.

Carlsoo, s. Nervous Cordination and Mechanical Function of the Mandibular Elevators. An Electromyographic Study of the Activity and an Anatomic Analysis of the Mechanics of the Muscles. Acta Odont. Scand., 1952, 10: (Supp. 11)

An Electromyographic study of the Activity of Certain Suprahyoid Muscles and of the Reciprocal Innervation of the Elevator and Depressor Musculature of the Mandible. Acta. Anat., 1956, 26:81-93.

Cuozzo, J.W. A Correlation of the Functions and Diameters of the Sensory Fibers in the Inferior Alveolar Nerve of the Cat. M.S. Thesis, Loyola University, Chicago, 1966, pp. 51 .

Eisenman, J., Landgren, S., and Novin, D. Functional Organization in the Main Sensory Trigeminal Nucleus and in the Rostral Subdivision of the Nucleus of the spinal Trigeminal Tract in the Cat. Acta Physiol., Scand., 1963, 59 (Supp. 214) :1-44. 
Greenfield, B.E. and Wyke, B.D。 Electromyographic Studies of Some of the Muscles of Mastication. Brit. Dent. J., 1956, 100:129-143。

Harrison, R. and Corbin, R.B. Function of the Mesencephalic Root of Fifth Cranial Nerve. J. Neurophysiol. 1940 , 5:423-435.

- The Central Pathway for the Jaw Jerk. Amer. J. Physiol., 1942, 135:439-445.

Hickey, J.C., Stacy, R.W., Rinear, L.L. Electromyographic Studies of Mandibular Muscles in Basic Jaw Movements. $1957,7: 565-576$.

Jarabak, J.R. The Adaptability of the Temporal and Masseter Muscles; an Electromyographic Study. Angle Orthodont. , 1954, 24:193-213.

Jerge, C.R. Organization and Function of the Trigeminal Mesencephalic Nucleus, J. Neurophysiol., 1963, $26: 379-392$.

Kawamura, Y. Recent Concepts of the Physiology of Mastication. Adv. Oral Biol., 1964, 1:77-109。

Kawamura, Y., Funakoshi, M., and Tsukamoto, S. Brainstem Representation of Jaw Muscle Activities of the Dog. Jap. J. Physiol., 1958, 8: 292-304.

Kawamura, Y., Funakoshi, M., Tsukamoto, S., and Takata, M. Brainstem Mechanism Controliins the Jaw Muscle Tonus of the Dog. Jap. J. Physiol., 1959, $9: 453-463$.

Kizior, J.A. Histologic and Physiologic Investigation of the Sensory Receptors in the Periodontal Ligament of the Cat. M.S. Thesis, Loyola University, Chicago, 1966, pp. 31. 
Kruger, L. and Michel, F. A Single Neuron Analysis of Buccal Cavity Representation in the Sensory Trigerinal Complex of the Cat. Arch. Oral Biol., $1962,7: 491-503$.

Latif, A. An Electromyographic Study of the Temporalis Muscle in Normal Persons During Selected Positions and Movements of the Mandible. Amer. J. Ortho., 1957, 43: 577-591.

Loewenstein, W.R. and Rathkamp, R.A. Study on the Pressoreceptive Sensibility of the Tooth. J. Dent. Res., 1955, 34:287-294.

MacDougall, J. and Andrew, B. Electromyographic Study of the Temporalis Muscles. J.Anat., 1953, $87: 37-45$.

Moyers, R.E. Electromyographic Analysis of Muscles in Temporomandibular Movement. Amer. J. Ortho., 1950 , 36:481-513.

Ness, A.R. The Mechanoreceptors of the Rabbit Mandibular Incisor. J.Physiol., 1954, 126:475-493.

Perry, H.T. and Harris, S.C. Role of the Neuromuscular System in Functional Activity of the Mandible. J.Amer. Dent. Assoc., 1954, 48:665-673.

Pfaffmann, C. Afferent Impulses from the Teeth Due to Pressure and Noxious Stimulation. J. Physiol., 1939, 15:3-34.

Ruch, T.C. and Patton, H.D. Physiology and Biophysics. ed. 19, Philadelphia, 1965, W.B. Saunders, pp. 129.

Schaerer, D. and Stallard, R.E. Analog Computation of Electromyographic Muscle Response During Mastication. Helv. Odont. Acta, 1965, 9(1):87-90. 
87

Sherrington, C.S. Reflexes Elicitable from Pinna, Vibrissae, and Jaws of the Cat. J. Physio., 1917, 51:404-431.

Stewart, D. Some Aspects of the Innervation of the Teeth. Proc. Roy. Soc. Med., 1927, $20(3)$ : $1675-1686$.

Szentagothai, J。 Anatomical Considerations of Monosynaptic Reflex Arcs. J. Neurophysiol., 1948, 11:445-454.

Pulley, W.J. Methods of Recording Patterns of Behavior of the Oro-Facial Muscles Using the Electromyograph. Dent. Rec., 1953, 73:741-748.

Vaughan, H.C. The External Pterygoid Mechanism 。 J。 Pros. Dent., 1955, 5:80-92. 
APPROVAL SHEET

The thesis submitted by Frederick R. Marg has been read and approved by the three members of his examining board.

The final copies have been examined by the Director of the thesis and the signature which appears below verifies that any necessary changes have been incorporated and that the thesis is now given final approval with reference to content, form and mechanical accuracy.

The thesis is therefore accepted in partial furlfillment of the requirements for the degree of Master of Science.
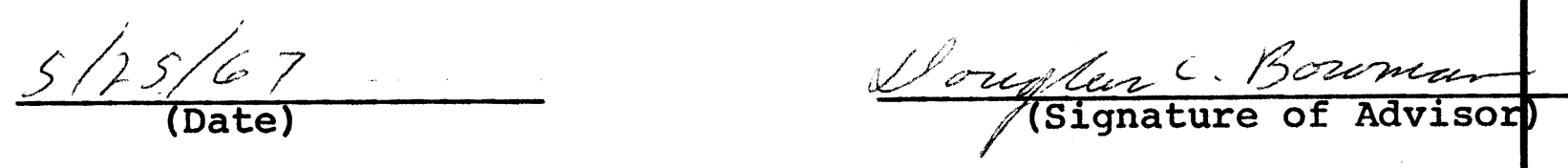